\title{
Retinal Wave Patterns Are Governed by Mutual Excitation among Starburst Amacrine Cells and Drive the Refinement and Maintenance of Visual Circuits
}

\author{
Hong-Ping Xu, ${ }^{1 \star}$ Timothy J. Burbridge, ${ }^{1 \star}$ Meijun Ye, ${ }^{2}$ Minggang Chen, ${ }^{2}{ }^{\odot X i n x i n ~ G e, ~}{ }^{1}$ Z. Jimmy Zhou, ${ }^{1,2,3}$ \\ and Michael C. Crair ${ }^{1,2}$ \\ Departments of ${ }^{1}$ Neuroscience, ${ }^{2}$ Ophthalmology and Visual Science, and ${ }^{3}$ Cellular and Molecular Physiology, Yale University School of Medicine, New \\ Haven, Connecticut 06520
}

Retinal waves are correlated bursts of spontaneous activity whose spatiotemporal patterns are critical for early activity-dependent circuit elaboration and refinement in the mammalian visual system. Three separate developmental wave epochs or stages have been described, but the mechanism(s) of pattern generation of each and their distinct roles in visual circuit development remain incompletely understood. We used neuroanatomical, in vitro and in vivo electrophysiological, and optical imaging techniques in genetically manipulated mice to examine the mechanisms of wave initiation and propagation and the role of wave patterns in visual circuit development. Through deletion of $\beta 2$ subunits of nicotinic acetylcholine receptors ( $\beta 2$-nAChRs) selectively from starburst amacrine cells (SACs), we show that mutual excitation among SACs is critical for Stage II (cholinergic) retinal wave propagation, supporting models of wave initiation and pattern generation from within a single retinal cell type. We also demonstrate that $\beta 2$-nAChRs in SACs, and normal wave patterns, are necessary for eye-specific segregation. Finally, we show that Stage III (glutamatergic) retinal waves are not themselves necessary for normal eye-specific segregation, but elimination of both Stage II and Stage III retinal waves dramatically disrupts eye-specific segregation. This suggests that persistent Stage II retinal waves can adequately compensate for Stage III retinal wave loss during the development and refinement of eye-specific segregation. These experiments confirm key features of the "recurrent network" model for retinal wave propagation and clarify the roles of Stage II and Stage III retinal wave patterns in visual circuit development.

Key words: activity-dependent; eye-specific segregation; recurrent network; retinal waves; spontaneous activity; starburst amacrine cells

\section{Significance Statement}

Spontaneous activity drives early mammalian circuit development, but the initiation and patterning of activity vary across development and among modalities. Cholinergic "retinal waves" are initiated in starburst amacrine cells and propagate to retinal ganglion cells and higher-order visual areas, but the mechanism responsible for creating their unique and critical activity pattern is incompletely understood. We demonstrate that cholinergic wave patterns are dictated by recurrent connectivity within starburst amacrine cells, and retinal ganglion cells act as "readouts" of patterned activity. We also show that eye-specific segregation occurs normally without glutamatergic waves, but elimination of both cholinergic and glutamatergic waves completely disrupts visual circuit development. These results suggest that each retinal wave pattern during development is optimized for concurrently refining multiple visual circuits.

\section{Introduction}

A fundamental feature of developing neural circuits is the presence of patterned spontaneous activity that drives early circuit growth and organization (Blankenship and Feller, 2010; Kirkby

Received Sept. 21, 2015; revised Feb. 16, 2016; accepted Feb. 18, 2016.

Author contributions: H.-P.X., T.J.B., Z.J.Z., and M.C.C. designed research; H.-P.X., T.J.B., M.Y., M.C., and X.G. performed research; H.-P.X., T.J.B., M.Y., M.C., and X.G. analyzed data; H.-P.X., T.J.B., Z.J.Z., and M.C.C. wrote the paper. et al., 2013; Ackman and Crair, 2014). In the visual system, spontaneous retinal activity is patterned in a wave-like manner and propagates coherently through multiple levels of the visual path-

This work was supported by National Institutes of Health Grants T32 NS007224, R01 EY015788, and R01 EY023105 to M.C.C. and Grants R01 EY017353, R01 EY026065, and T32 EY022313 to Z.J.Z., and in part by Research to Prevent Blindness unrestricted Department of Ophthalmology grant. M.C.C. was supported by the William Ziegler III family. We thank Yueyi Zhang and all members of the M.C.C. laboratory for their helpful comments on the work and manuscript.

The authors declare no competing financial interests. 
way (Goodman and Shatz, 1993; Weliky and Katz, 1999; Huberman et al., 2008; Ackman et al., 2012; Feller, 2012; Siegel et al., 2012). These so-called "retinal waves" are separated into three developmental stages and are the most common model of early activity-dependent plasticity in the nervous system.

Stage I waves, which are prenatal in mice, are thought to be mediated by GAP junctions but are the least studied and are still very poorly understood (Bansal et al., 2000; Syed et al., 2004). Stage II waves occur during the first postnatal week in mice, are mediated by acetylcholine receptors, and are critical for the development of precise connections within and between the retina and brain (Feller et al., 1996; Penn et al., 1998; Rossi et al., 2001; Feller, 2002, 2009; Grubb et al., 2003; McLaughlin et al., 2003; Chandrasekaran et al., 2005; Mrsic-Flogel et al., 2005; Torborg et al., 2005; Burbridge et al., 2014). The specific spatiotemporal features of Stage II waves also influence circuit development ( $\mathrm{Hu}-$ berman et al., 2008; Xu et al., 2011, 2015; Burbridge et al., 2014), emphasizing the importance of understanding the detailed mechanisms responsible for wave generation and propagation. Stage II waves are initiated by the spontaneous depolarization of starburst amacrine cells (SACs), and recurrent network models for wave propagation postulate that spontaneous activity emerges from an interplay between the intrinsic electrical properties of SACs and their mutual interconnectivity (Feller et al., 1997; Butts et al., 1999; Zheng et al., 2004, 2006; Godfrey and Eglen, 2009; Hennig et al., 2009; Blankenship and Feller, 2010; Ford et al., 2012). However, the precise mechanism responsible for the spatiotemporal pattern of retinal waves and their propagation, especially the relative contributions of cholinergic synapses between SACs and from SACs to ganglion cells, remains uncertain because of the inherent difficulty of selectively blocking cholinergic communication either within or between individual cell types.

We sought to test recurrent network models of wave propagation by examining the spatiotemporal properties of spontaneous activity in mice that have cholinergic neurotransmission blocked specifically in SACs. Because of age-dependent Cre expression driven by the ChAT promoter, we deleted $\beta 2$-nAChRs from a steadily increasing population of SACs during early postnatal development and analyzed the effect on cholinergic wave propagation and circuit refinement. We found that retinal wave area decreased in parallel with the increasing population of Creexpressing SACs both in vitro and in vivo, demonstrating that wave propagation is directly governed by cholinergic communication among the network of mutually interconnected SACs. We similarly found that activity in SACs and nearby retinal ganglion cells (RGCs) is less synchronized after elimination of $\beta 2$ subunits from SACs, with RGCs demonstrating "extra" activity beyond that observed in near neighbor SACs in conditional knock-outs. We also examined the effects of these novel genetic manipulations on central visual circuit refinement and found that the gradual loss of $\beta 2$ subunits in SACs caused deficits in eye-specific segregation in both the dorsal lateral geniculate nucleus (dLGN) and superior colliculus (SC) at postnatal day 8 , but that segregation recovered at $\mathrm{P} 15$ following a period of Stage III (glutamate-mediated) retinal waves. Interestingly, elimination of Stage III waves in addition to the conditional deletion of $\beta 2$ -

*H.P.X. and T.J.B. contributed equally to this work.

Correspondence should be addressed to Dr. Michael C. Crair, Department of Neuroscience, Yale University School of Medicine, SHM B301, 333 Cedar Street, New Haven, CT 06520. E-mail: michael.crair@yale.edu.

DOI:10.1523/JNEUROSCI.3549-15.2016

Copyright $\odot 2016$ the authors $\quad 0270-6474 / 16 / 363872-16 \$ 15.00 / 0$
nAChRs from SACs prevented this recovery, whereas eliminating only Stage III waves had no effect on eye-specific segregation so long as the period of Stage II retinal waves extended through the second postnatal week. This implies that the specific and distinct properties of Stage III retinal waves are not necessary for the maintenance and continued refinement of eye-specific segregation (Demas et al., 2006; Xu et al., 2010). Together, this work provides experimental support for the recurrent network model of cholinergic retinal wave propagation and suggests that glutamatergic retinal waves are important for the emergence of distinct features of visual circuit development apart from eyespecific segregation.

\section{Materials and Methods}

Animals. All experimental procedures were in accordance with National Institutes of Health guidelines and approved by Yale Institutional Animal Care and Use Committees. Animals were treated in compliance with the U.S. Department of Health and Human Services and Yale University School of Medicine. ChAT-Cre mice (B6.129S6-ChAT ${ }^{\text {tm 1(cre)Lowl } / J) ~ w e r e ~}$ purchased from The Jackson Laboratory (stock\#018957). Cre expression in these mice is by virtue of an IRES-Cre sequence inserted downstream of the stop codon in the endogenous ChAT gene promoter, such that ChAT gene expression is unaffected (Rossi et al., 2011). $\beta 2$-nAChR floxed mice were generated in our laboratory (Burbridge et al., 2014). These mice possess loxP sites flanking $\sim 2.2 \mathrm{~kb}$ of sequence of the targeted Chrnb2 gene that contains exon 5, the largest coding exon ( $970 \mathrm{bp}$ ) of the gene. Mice lacking $\beta 2$ (Chrnb2) in cholinergic neurons ( $S A C-\beta 2-c K O s$ ) were generated by crossing $\beta 2$-floxed $\left(\beta 2^{\mathrm{fl} / \mathrm{fl}}\right)$ mice with ChAT-Cre mice using the breeding scheme previously described (Li et al., 2013; Burbridge et al., 2014; Xu et al., 2015). In brief, ChAT-Cre mice were crossed to $\beta 2$-null mice to generate $\mathrm{ChAT}-\mathrm{Cre}^{+} ; \beta 2^{+/-}$, which were then crossed to $\beta 2^{\mathrm{fl} / \mathrm{fl}}$ mice to obtain $S A C-\beta 2-c K O$ mice $\left(\mathrm{ChAT}-\mathrm{Cre}{ }^{+}\right.$; $\left.\beta 2^{\mathrm{fl} /-}\right)$, littermate WT $\left(C h A T-C r e^{-} ; \beta 2^{\mathrm{fl} /+}\right)$, and heterozygous $(S A C-$ $\mathrm{Cre}^{+} ; \beta 2^{\mathrm{fl} /+}$ and $\left.\mathrm{ChAT}-\mathrm{Cre}^{-} ; \beta 2^{\mathrm{fl} /-}\right)$ controls. Vesicular glutamate transporter 1 (Vglut1 or Slc17a7) heterozygous mice (Fremeau et al., 2004) were obtained from Robert Edwards at University of California at San Francisco. Mice of either sex were used in all experiments.

Tissue-specific Cre expression was confirmed by crossing the ChATCre mice to a CAG-CAT-EGFP (Kawamoto et al., 2000) reporter mouse. At the indicated ages, retinas were collected and reporter (GFP) expression was analyzed. In brief, isolated retinas were fixed in $4 \%$ PFA, cryoprotected in $30 \%$ sucrose in $1 \times$ PBS, and then blocked with $10 \%$ normal donkey serum and 5\% BSA in PBS containing $0.05 \%$ Triton X-100 overnight at $4^{\circ} \mathrm{C}$. Retinas were then incubated in rabbit anti-GFP conjugated to AlexaFluor-488 (Invitrogen, A21311) and goat anti-ChAT antibodies (Millipore, $\mathrm{AB} 144 \mathrm{P}$ ) in blocking solution at $4^{\circ} \mathrm{C}$ for $\sim 48 \mathrm{~h}$. After washing three times with $1 \times$ PBS, retinas were incubated in a donkey anti goat secondary antibody conjugated with Rhodomine for $2 \mathrm{~h}$ at room temperature. After 3 times washing with $1 \times$ PBS, retinas were mounted with Fluromount-G.

In vitro retinal wave recording using multielectrode arrays. Spiking retinal activity was recorded in vitro at $\mathrm{P} 4$ using a multielectrode array (MultiChannel Systems, Reutlingen) at $34^{\circ} \mathrm{C}$ in Ringer's solution containing the following (in mM): $124 \mathrm{NaCl}, 2.5 \mathrm{KCl}, 2 \mathrm{CaCl}_{2}, 2 \mathrm{MgCl}_{2}, 1.25$ $\mathrm{NaH}_{2} \mathrm{PO}_{2}, 26 \mathrm{NaHCO}_{3}$, and 22 glucose, pH 7.35, and oxygenated with $95 \% \mathrm{O}_{2}$ and $5 \% \mathrm{CO}_{2}$. Action potentials were simultaneously recorded from 60 electrodes spaced $100 \mu \mathrm{m}$ apart. The signals were filtered between $100 \mathrm{~Hz}$ and $3 \mathrm{kHz}$. Offline data analysis was performed using Offline Sorter (Plexon), NeuroExplorer (Nex Technologies), and a custom MATLAB program (MATLAB and Statistics Release, 2012b, The MathWorks). A number of retinal wave properties were measured, including neuronal firing rate, correlation, wave frequency, and wave size. Firing rate was calculated either by spiking frequency during the entire recording period or during a particular wave, where appropriate. The spike time tiling coefficient (STTC), a measure of correlated activity between cells, was calculated as previously described (Cutts and Eglen, 2014). Briefly, it was determined by calculating the number of spikes from cell A that fall within a specified time window of a spike from cell $B$. 
$\mathrm{STTC}=(1 / 2)((\mathrm{PA}-\mathrm{TB}) /(1-\mathrm{PATB})+(\mathrm{PB}-\mathrm{TA}) /(1-\mathrm{PBTA}))$ where $\mathrm{PA}=$ the proportion of spikes from cell $\mathrm{A}$, which lie within $\pm \Delta \mathrm{t}$ of any spike from cell $\mathrm{B}$, and vice versa for $\mathrm{PB}$; $\mathrm{TA}=$ the proportion of total recording time which lies within $\pm \Delta$ t of any spike from $A$, and vice versa for TB (Cutts and Eglen, 2014). The STTC "Random" baseline was calculated from random shuffling of the $c K O$ and cHet MEA datasets used for calculating the STTC. All spike times recorded from one electrode were shifted by adding the same random time to each spike while keeping the same starting and ending time. Different electrodes were shifted with different random values.

Patch-clamp recording. Patch-clamp recording was used to test the cholinergic excitation and the synaptic inputs of SACs and RGCs. For the examination of acetylcholine currents, whole-cell recordings were performed on displaced SACs and RGCs in the whole-mount retina at $32^{\circ} \mathrm{C}-$ $34^{\circ} \mathrm{C}$ in oxygenated $\left(95 \% \mathrm{O}_{2}-5 \% \mathrm{CO}_{2}\right)$ ACSF (containing the following in mм: $125 \mathrm{NaCl}, 2.5 \mathrm{KCl}, 2 \mathrm{CaCl}_{2}, 1 \mathrm{MgCl}_{2}, 1.25 \mathrm{NaH}_{2} \mathrm{PO}_{4}, 0.5$ L-glutamine, $26 \mathrm{NaHCO}_{3}$, and 20 glucose, $\mathrm{pH} 7.4$ ) and pipette solution (containing the following in mM: $105 \mathrm{CsMeSO}_{4}, 0.5 \mathrm{CaCl}_{2}, 10 \mathrm{HEPES}, 5$ EGTA, $5 \mathrm{Na}_{2}$-phosphocreatine, 2 ATP-Mg, 0.5 GTP-2Na, 2 ascorbic acid, 8 QX314-Cl, pH 7.2). Nicotinic currents, evoked by puff application (300 ms, Picospitzer-II, General Valve) of 1.1-dimethyl-4-phenyl piperazinium iodide (DMPP; $1 \mathrm{mM}$ ), were recorded under voltage clamp at a holding potential of $-70 \mathrm{mV}$, using an EPC9-2 amplifier (Heka Elektronic). All recordings were made in the presence of $300 \mu \mathrm{M} \mathrm{CdCl}$ for the purpose of blocking synaptic transmission. Paired patch recordings were performed on SACs and RGCs. Whole-cell recordings were applied for study of EPSCs, and loose patch was used to examine the spiking activity.

In vivo calcium imaging. AAV virus encoding GCaMP6 was injected into eyes at $\mathrm{P} 0$, and spontaneous retinal activity was recorded from axonal terminals of infected RGCs at P5-P6 from SC. The procedure of surgery and imaging has been described in detail previously (Ackman et al., 2012; Burbridge et al., 2014). In brief, mice aged P5-P6 were deeply anesthetized with isoflurane $(2.5-3.5 \%)$ in oxygen and then placed on a heating pad set to $37^{\circ} \mathrm{C}$ using a homeothermic temperature monitor (NPI TC-20, ALA Scientific). Carprofen (Rimadyl, Pfizer, $50 \mathrm{mg} / \mathrm{ml}$ ) was injected subcutaneously to induce general analgesia, and local anesthesia was produced by subcutaneous injections of a mixture of $0.4 \%$ marcaine and $0.4 \%$ lidocaine (bupivacaine $\mathrm{HCl}$, Hospira, and lidocaine injectable, Sparhawk Laboratories) under the scalp. After removal of the scalp, steel head posts were fixed to the anterior and posterior portions of the exposed skull using vet-bond and cyanoacrylate glue, and a craniotomy window was made for the exposure of SC. Isoflurane anesthesia was adjusted during surgery as necessary to maintain a stable respiration rate. In vivo calcium imaging was conducted through the craniotomy window after a $1-2 \mathrm{~h}$ recovery from isoflurane anesthesia and the surgical procedure. Spontaneous wave activity was recorded from the SC under a $2.5 \times$ objective, and image frames containing both SC hemispheres were acquired at a rate of $5 \mathrm{~Hz}$. Epifluorescent illumination was provided by a mercury light source (X-Cite Series 120, EXFO) through a neutraldensity filter and a filter-cube set (U-MGFPHQ, Olympus) with the minimum illumination intensity that still gave detectable calcium signals using a CCD exposure of $200 \mathrm{~ms}$. A 12-bit CCD camera (Pixelfly, Cooke) coupled to an Olympus BX51 was used to image calcium responses.

Calcium-signal detection and image processing of spontaneous wave activity were performed using custom software routines written in MATLAB (The MathWorks), which has been described in detail previously (Ackman et al., 2012). Briefly, a rectangular grid of regions of interest (ROIs) (for each ROI, height $=45 \mathrm{~mm}$, width $=45 \mathrm{~mm}, 10 \times 10$ pixels) was masked over the average image, $\mathrm{F}_{0}$, of visible calcium indicator fluorescence for each movie. Calcium signals for each ROI were the average fluorescence intensity inside each ROI in each frame, $F_{t}$, measured as a function of time $\left(\mathrm{DF} / \mathrm{F}=\left(\mathrm{F}_{\mathrm{t}}-\mathrm{F}_{0}\right) / \mathrm{F}_{0}\right)$. Calcium transients were detected using automatic unbiased detection routines to identify local maxima ( $>2$ SDs of the derivative of the signal). A waveform representing the population activity for each movie was constructed by smoothing the envelope of the population activity histogram for each movie with a 10-order Hanning filter. Local maxima separated by $>10 \mathrm{~s}$ and having rising phase onsets surpassing a 5\% population activity threshold from the local minima were set as wave peak and onset times, respectively. The time between the wave peak and the next local minima when population activity during the falling phase decreased to $<20 \%$ was set as the wave offset. Each wave period was then interactively confirmed based on the visually detected waves in the raw movie data. Any detected calcium transients occurring outside of wave periods were excluded from further analysis. The wave area was the sum of non- 0 areas within the merged wave. Wave frequencies for each recording were calculated as the number of waves divided by the length of time for each recording. Interwave intervals for each recording were calculated as the set of time intervals between the onsets of sequential waves in each recording. Pixel intensity within each wave period was normalized, and pixel numbers above threshold at 0.1-0.9 were calculated, with wave peak correlation index equaling pixel numbers at wave peak divided by the total number of pixels activated throughout each wave.

Dye injections, fluorescent images, and data analysis. Measurements of eye-specific segregation were performed with whole eye injections $(1 \mu \mathrm{l}$ into the vitreous) of cholera toxin subunit B (CTB) conjugated to AlexaFluor (Invitrogen), CTB-488 and CTB-555, into the left eye and the right eye, respectively, using a Nanoject (Drummond Scientific) to bulk label all RGCs. Pups were anesthetized with a veterinary anesthetic mixture $(4.28 \mathrm{mg} / \mathrm{ml}$ ketamine, $0.82 \mathrm{mg} / \mathrm{ml}$ xylazine, and $0.07 \mathrm{mg} / \mathrm{ml}$ acepromazine) at either P6 or P13. The injected pups were allowed to recover from anesthesia and then put back with their mother for $48 \mathrm{~h}$ to allow transport of tracer from the retina to the SC and dLGN. Mice were killed and intercardially perfused with 4\% PFA in PBS $48 \mathrm{~h}$ later. The entire brain was further fixed overnight, sectioned at $150 \mu \mathrm{m}$ either sagitally (for SC images) or coronally (for dLGN images) on a vibratome (Leica, VT100S), and imaged using a CCD camera (AxioCam HRC, Carl Zeiss). Eye-specific segregation in the SC was quantified by measuring the fraction of fluorescence signal labeled from the ipsilateral eye in the stratum griseum superficial (SGS) layer, where axons only from the contralateral eye usually terminate. The total SGS was outlined manually based on fluorescence signals, and the fraction of the ipsilateral eye projection and overlap was calculated at the various reported thresholds. The quantification of eye-specific segregation in the dLGN followed previously published methods (Stellwagen and Shatz, 2002; Huberman et al., 2003; Xu et al., 2011). Briefly, three sections that contained the largest ipsilateral projection, corresponding to the central third of the dLGN, were selected, and data were averaged across these sections. The fraction of pixels in the dLGN that contained ipsilateral labeling, contralateral labeling, and both ipsilateral and contralateral labeling (overlapping) were calculated at different thresholds and reported as the "fraction of ipsilateral projection," "fraction of contralateral projection," and "fraction of overlap," respectively. The Segregation index was calculated using methods that are threshold-independent, as described by Torborg et al. (2005). The intensity ratio for each pixel was computed as $r=$ $\log _{10}\left(\mathrm{~F}_{\mathrm{I}} / \mathrm{F}_{\mathrm{C}}\right)$, where $\mathrm{F}_{\mathrm{I}}$ and $\mathrm{F}_{\mathrm{C}}$ are fluorescence intensities from the ipsilateral and contralateral projections, respectively, and the variance of the $\mathrm{R}$ distribution, which we refer to as the Segregation index, was calculated from these values. High R variance (Segregation index) indicates more contralateral only and ipsilateral only dominant pixels and, therefore, more eye segregation.

Statistics. Student's $t$ tests were used when two groups were compared (see Figs. 1-7), and ANOVA tests were used for multiple comparisons with Tukey's honest significant difference (HSD) test to determine significance (see Fig. 5). The $F$ test of equality of variances was used to compare DMPP-induced SAC activity in Figure 2. KolmogorovSmirnov tests were used to compare cumulative distributions in Figures 3 and 4. All means in the text are reported with SDs, but error bars in figures indicate SE. In figures that display a box plot (see Fig. 2C), the box edges are first and third quartile, whiskers are $1.5 \times$ the interquartile range, and the midline is median value.

\section{Results}

The expression of $\beta 2-n A C h R s$ in the retina has been genetically manipulated in a number of ways, with each manipulation influencing wave propagation and dynamics differently. Animals with germline deletion of $\beta 2$-nAChRs $(\beta 2-K O)$ lack any cholinergic 
activity during the first postnatal week. Inconsistent reports of noncholinergic spontaneous activity were noted in vitro in 32-KO mice (Bansal et al., 2000; Sun et al., 2008; Stafford et al., 2009), whereas a recent in vivo study demonstrates that only very low levels of patterned, noncholinergic spontaneous activity persists in $\beta 2-K O s$ (Burbridge et al., 2014). The altered spatiotemporal features of activity in $\beta 2-K O$ mice also severely disrupt retinofugal eye-specific segregation and retinotopic refinement, even while wave frequency is unchanged. Altered activity in $\beta 2-K O$ mice seems to preferentially disrupt retinotopic map formation, as rescue of wave frequency alone partially rescues eyespecific segregation but has no effect on retinotopic maps, indicating that different aspects of waves are important for different circuit refinement features (Burbridge et al., 2014). These results suggest that $\beta 2$-containing $\mathrm{nAChRs}$ are essential for maintaining the specific wave patterns that are in turn necessary for the normal development of visual circuits in the brain. In $\beta 2(T G)$ mice, $\beta 2$-nAChRs are strongly expressed in the RGC layer and only sparsely in the inner nuclear layer (Xu et al., 2011). The firing rate of RGCs in $\beta 2$ (TG) mice is normal, but waves are much smaller, possibly because $\beta 2$-nAChRs are expressed in only a limited subset of retinal neural types, thereby truncating, but not eliminating, wave propagation. However, due to the inherent limitations of in situ hybridization (Xu et al., 2011) and the absence of a specific antibody for $\beta 2$ subunits of nAChRs (Moser et al., 2007), the exact population of neural types that express $\beta 2$ in the $\beta 2(T G)$ mice is not clear, making it impossible to elucidate how wave patterns are generated in the developing cholinergic network. Pax $6 \alpha-\beta 2-c K O$ mice, which lack $\beta 2-n A C h R s$ in distinct topographic regions of the retina across all neural layers, have no spontaneous activity in those topographic regions that lack $\beta 2$ expression, and show disrupted downstream circuit refinement in matched retinotopic regions (Burbridge et al., 2014). $R x-\beta 2-$ cKO mice, on the other hand, have greatly reduced cholinergic spontaneous activity due to the absence of $\beta 2$-nAChRs in $\sim 80 \%$ of retinal neurons across the inner retina (Xu et al., 2015). These various manipulations reduced activity levels and/or disrupted spatiotemporal patterns of cholinergic retinal waves, which in turn impaired axonal projections of RGCs to the dLGN and the $\mathrm{SC}$, and therefore provide convincing evidence for an instructive role of spontaneous retinal activity in retinofugal visual circuit development. However, these manipulations failed to specifically address the mechanism of retinal wave propagation or explain how the spatiotemporal pattern of retinal waves is supported due to limited knowledge of $\beta 2$-nAChR expression in the retina (as in $\beta 2(T G)$ mice) and nonspecific deletion of $\beta 2$ from all retinal neural types (as in $\beta 2-K O s, R x-\beta 2-c K O s$, and Pax6 $\alpha-\beta 2-c K O$ mice).

\section{nAChRs are gradually eliminated from SACs by Cre/loxP recombination}

Mutual neurotransmission among SACs was selectively blocked by genetic deletion of $\beta 2$ subunits of nAChRs ( $\beta 2-n A C h R s)$ in SACs using Cre/loxP recombination. The conditional deletion of $\beta 2$ was achieved by crossing ChAT-Cre (Rossi et al., 2011) mice to floxed- $\beta 2$ mice (Burbridge et al., 2014). Based on GFP expression in reporter mice, Cre is exclusively expressed in SACs in the retina as early as postnatal day 2 (P2), and the population of Creexpressing SACs increases with age $(6.9 \%, 23.9 \%$, and $51.9 \%$ at P2, P4, and P8, respectively). At P10, almost all SACs (99.4\%) express Cre, and this expression is maintained into adulthood (Fig. $1 A, B$ ). To test the efficiency of Cre-mediated $\beta 2$-nAChRs excision, we recorded excitatory currents mediated by $\beta 2$ - containing AChRs from SACs (Fig. 1C). Puff application of DMPP (1 mM), a nonhydrolyzable nicotinic AChR agonist, to Cre (GFP) expressing SACs elicited excitatory currents that could be completely blocked by either $\mathrm{DH} \beta \mathrm{E}(20 \mu \mathrm{M})$ or hexamethonium (200 $\mu \mathrm{M}$; data not shown), two antagonists specific to nicotinic AChRs, in WT mice at P5 and P6. DMPP failed to induce $\mathrm{DH} \beta \mathrm{E}$-sensitive currents in SACs of germline $\beta 2$ knock-out mice $(\beta 2-K O s)$ at the same age, suggesting that DMPP acts via nicotinic AChRs specifically. In P5-P6 mice with $\beta 2$ deleted specifically from ChAT-Cre-positive SACs (SAC- $\beta 2$-cKOs), DMPP elicited a small inward current that was also blocked by $\mathrm{DH} \beta \mathrm{E}$ (data not shown). Currents elicited by DMPP were much smaller in $S A C-\beta 2-c K O s(29.1 \pm 25.7 \mathrm{pA}$ average) compared with those in WT controls at the same age $(86.1 \pm 60.4 \mathrm{pA}$ average), suggesting that functional nicotinic receptors were greatly reduced in $S A C-\beta 2-c K O$ mice at this age (Fig. $1 C ; \beta 2-K O$ average current $=$ $4.2 \pm 4.0 \mathrm{pA})$. The DMPP-elicited currents in $S A C$ - $\beta 2$ - $c K O$ s were not blocked by bungarotoxin ( $100 \mathrm{nM}$; $c K O+$ bungarotoxin average $=36.5 \pm 34.4 \mathrm{pA})$, an $\alpha 7$-specfic antagonist, or mimicked by cytisine $(500 \mu \mathrm{M} ; \beta 2-c K O+$ cytisine average $=3 \pm 3.8 \mathrm{pA})$, a $\beta 4$ subunit-specific agonist, suggesting that neither $\beta 4$ nor $\alpha 7$-composed nAChRs mediate the DMPP-induced inward currents in SACs of the SAC- $\beta 2-c K O s$ (Fig. $1 C$ ). The small nicotinic currents observed in SAC-cKO mice at P5-P6 were likely mediated by residual $\beta 2$-nAChRs in SACs due to protein persistence and/or partial Cre expression, which is not complete until $\sim \mathrm{P} 10$.

\section{Wave activity is truncated in $S A C-\beta 2-c K O$ mice}

Early retinal wave models used a variety of mechanisms to explain the slow propagation speeds, small size, and random initiation sites that were evident in the initial experimental descriptions of spontaneous retinal activity. Some models theorized that passive ionic diffusion could contribute to waves spreading between RGCs (Burgi and Grzywacz, 1994), but subsequent results localized wave initiation to SACs and led to two-layer recurrent network models that incorporated filtered communication between SACs and RGCs to explain the small wave size and lack of interwave RGC activity (Butts et al., 1999; for review, see Godfrey and Eglen, 2009). More recent models of Stage II (cholinergic) retinal waves focus on SACs for wave generation and propose that spontaneous activity in SACs is synchronized through a network of mutual synaptic communication among SACs mediated by $\beta 2$ nAChRs (Godfrey and Swindale, 2007; Hennig et al., 2009; Ford and Feller, 2012). These models vary in the mechanisms used to restrict wave propagation and size, mostly relying on different forms of the slow after-hyperpolarization that controls the rate of "spontaneous" depolarizations in individual SACs, but all predict that the size (area) of waves should decrease as the fraction of SACs expressing $\beta 2$-nAChRs decreases.

To test this hypothesis, we examined RGC spontaneous activity in $S A C-\beta 2-c K O$ mice, which have $\beta 2$-nAChRs gradually and specifically deleted from SACs over the course of the first week after birth. In WT mice at P4, RGC spiking activity is highly correlated, forming waves of propagating activity across the entire recording array (Fig. $1 D)$. In $S A C-\beta 2-c K O s$ at the same age, propagating waves rarely cover the whole recording array (Fig. 1E). Activity correlations between RGCs were reduced across a range of separations, and wave size was much smaller in $S A C-\beta 2-c K O$ s relative to WT controls (Fig. $1 F-H$; Table 1; P4 control wave size $=47.8 \pm 4.4 \%$ of array, $n=6$; P4 SAC- $\beta 2-c K O$ wave size $=21.9 \pm 6.1 \%$ of array, $n=9 ; p=1.48 \times 10^{-7}$, Student's $t$ test). Despite the differences in wave properties, RGC 

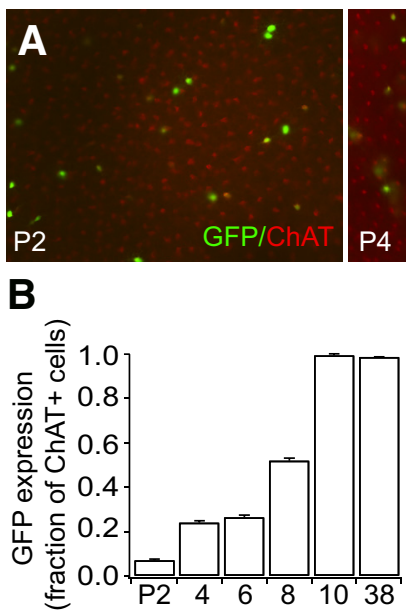

D

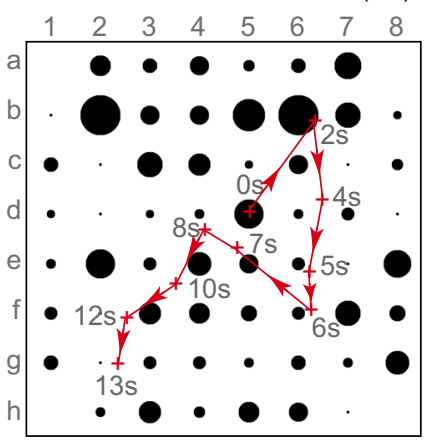

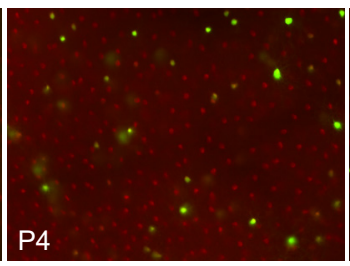

C $\operatorname{DMPP}(1 \mathrm{mM})$
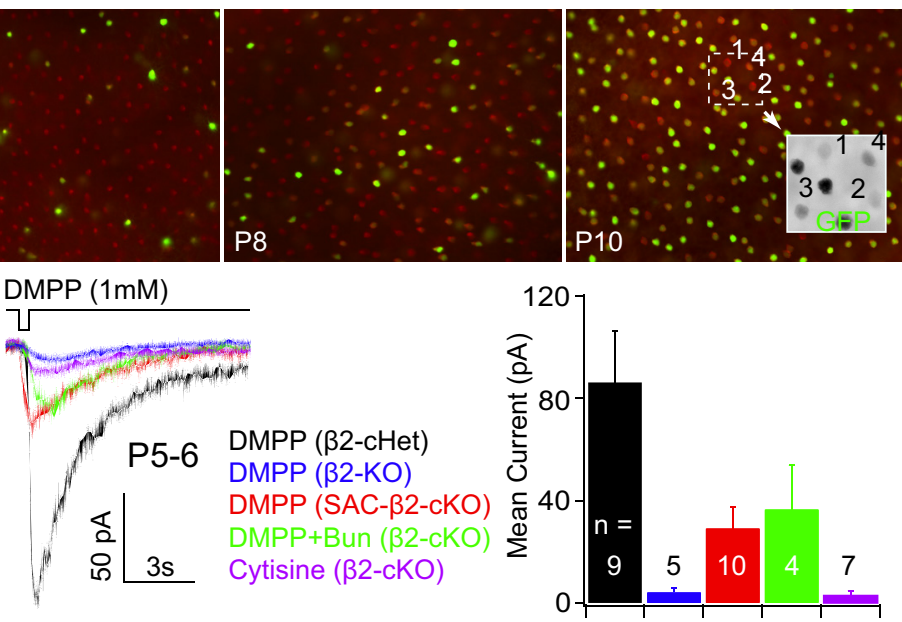

E
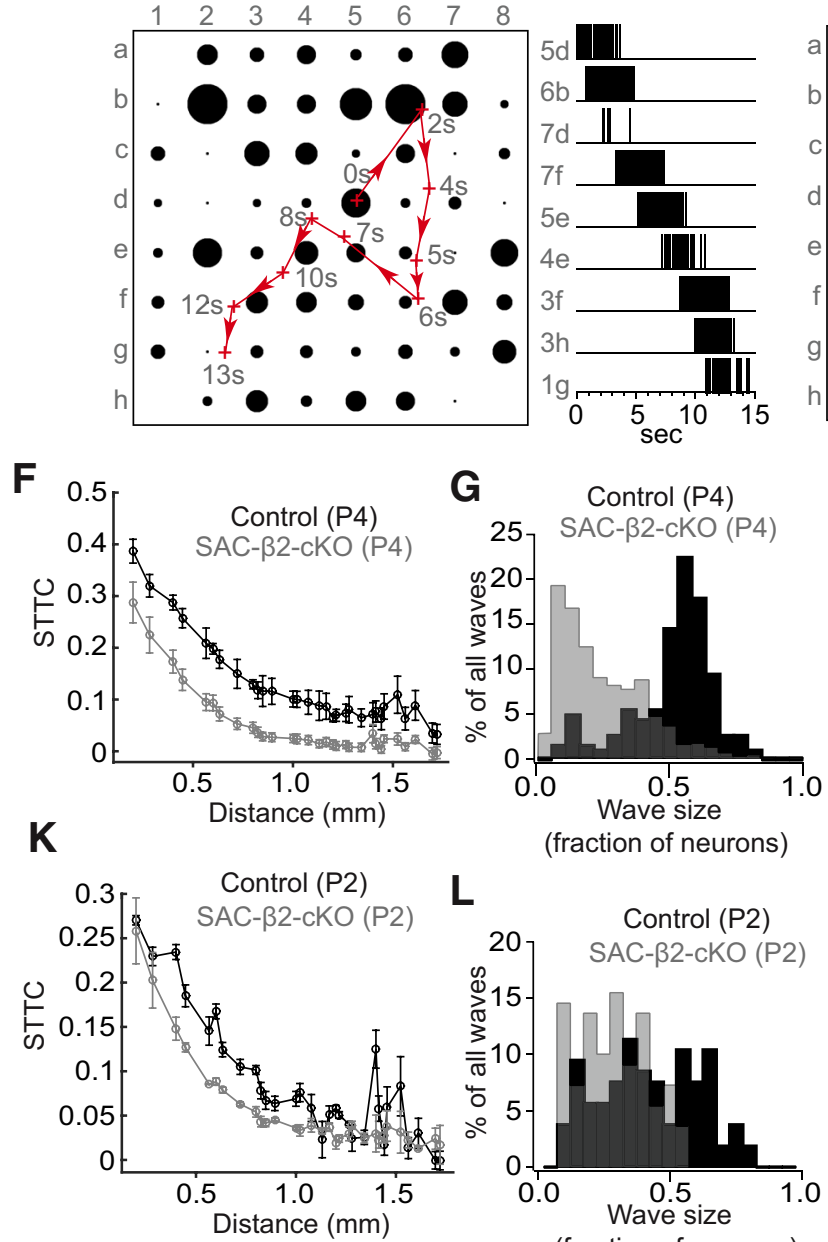

(fraction of neurons)
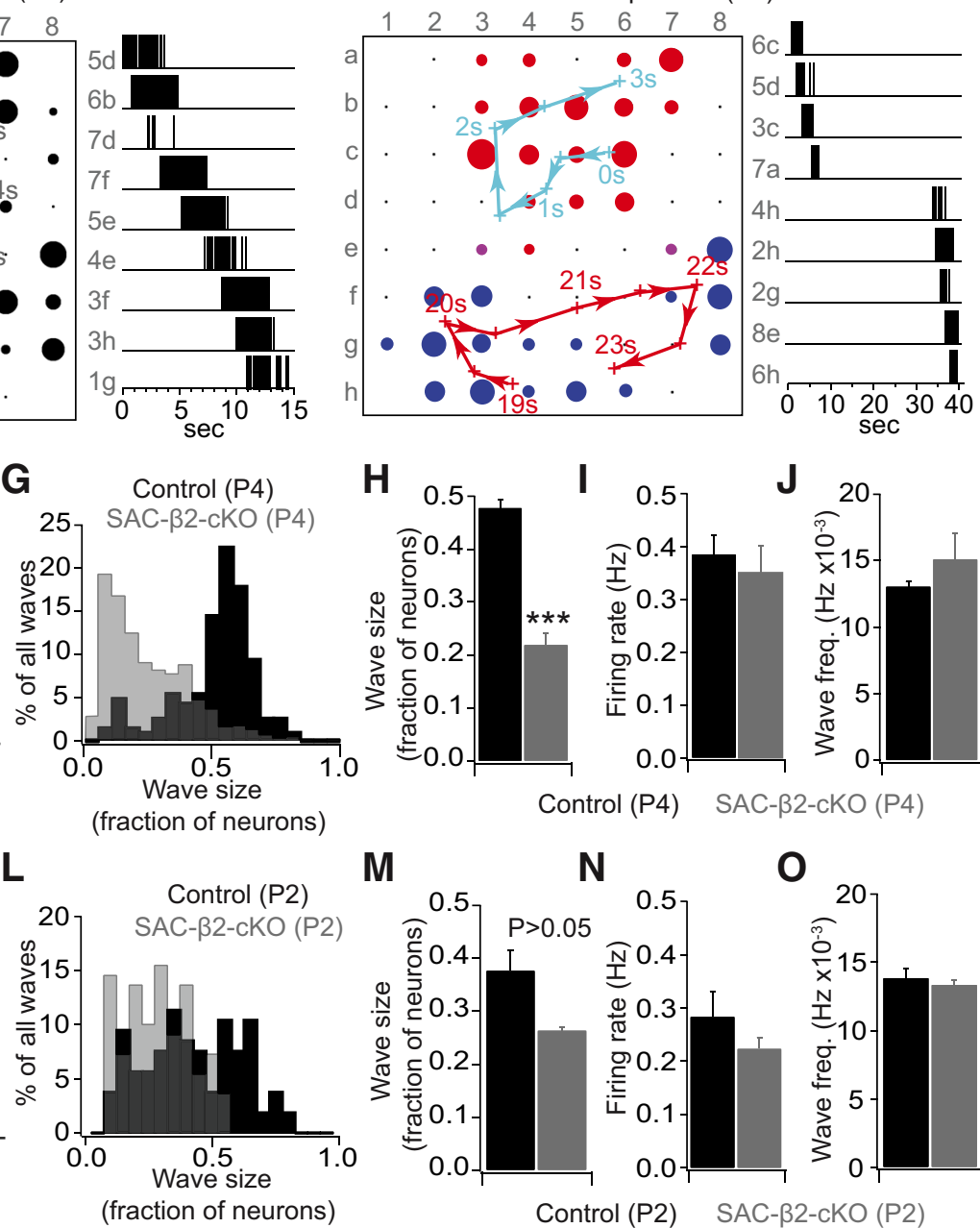

$M$

$\mathrm{N}$
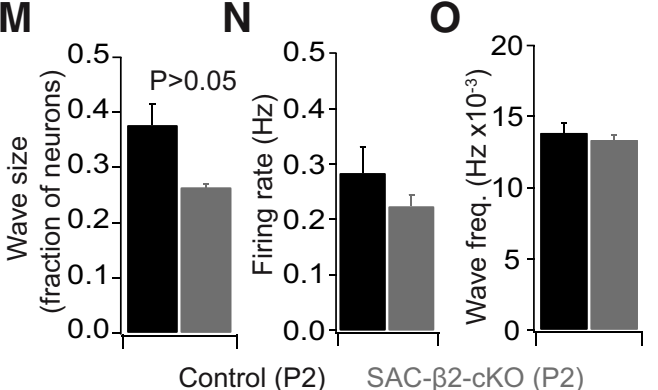

Figure 1. Age-dependent deletion of $\beta 2$-nAChRs from SACs disrupted spontaneous waves in vitro. A, Age-dependent Cre expression in SACs driven by the ChAT-promoter was visualized by the expression of a GFP reporter gene. SACs were also immunostained with an antibody against ChAT (red label). Expression increases from very few SACs at postnatal day 2 to the vast majority of cells at postnatal day 10. B, Quantification of the percentage of ChAT-positive (red) SACs that also express GFP (green), with coexpression increasing from 6.9\% at P2 to $99.4 \%$ at P10 and later. C, Example traces (left) and the mean amplitude (right) of nicotinic currents recorded from SACs from $\beta 2$-conditional heterozygous controls (ChAT-Cre ${ }^{+} / \beta 2^{\mathrm{fl} /+}: \beta 2$ - $\mathrm{CHet}$ ), $\beta 2 \mathrm{germline}$ deletion mice $(\beta 2-K 0)$, and SAC- $\beta 2-c K 0$ s at P5-P6. Puff application of DMPP (1 mM), a nicotinic AChR agonist, elicited excitatory currents in SACs recorded from $\beta 2$-heterozygous controls but not the $\beta 2-K 0$. DMPP induced smaller but considerable currents from SACs of SAC- $\beta 2-c K O$ s. The residual inward currents in SACs of SAC- $\beta 2-c K 0$ s were blocked by $20 \mu \mathrm{m}$ DH $\beta$ E, an antagonist specific to nicotinic AChRs, but not by bungarotoxin ( $100 \mathrm{~nm})$, an antagonist specific to $\alpha 7$-containing AChRs. Puff application of cytisine (500 $\mu \mathrm{m})$, a $\beta 4$ subunit specific agonist, failed to elicit currents on $S A C s$ of SAC- $\beta 2$-CKOs. D, Spontaneous RGC activity in a P4 retina of a control (ChAT-Cre $-/ \beta 2^{\mathrm{fl} /+}$ ) mouse recorded in Ringer's solution. Left, A spontaneous wave propagated across the entire multielectrode array in $15 \mathrm{~s}$, with most electrodes in the array participating in the wave. Red arrows indicate direction of weighted center of wave propagation. Black dots represent spiking activity recorded from that channel. Dot sizes represent relative mean activity level during the wave. Right, representative spiking activity of RGCs recorded from indicated electrodes. $\boldsymbol{E}$, Left, Two spontaneous waves (labeled in red and blue) in the recording area of a P4SAC- $\beta 2$-cKO mouse. Each wave was confined to a small region of the retina. Right, $40 \mathrm{~s}$ of representative spiking activity of RGCS recorded from indicated electrodes. $\boldsymbol{F}$, The STTC, a measure of correlated activity between cells, was slightly lower in SAC- $\beta 2$-cKOs than WT controls. $\mathbf{G}$, Histogram of wave (Figure legend continues.) 
Table 1. Properties of spontaneous activity in WT and SAC- $\beta 2-$ CKO $_{\text {mice during the first postnatal week }}{ }^{a}$

\begin{tabular}{|c|c|c|c|c|}
\hline & Contralateral P2 $(n=3)$ & CKOP2 $(n=3)$ & Contralateral P4 $(n=6)$ & CKOP4 $(n=9)$ \\
\hline Firing rate $(\mathrm{Hz})$ & $0.19 \pm 0.12$ & $0.19 \pm 0.03$ & $0.39 \pm 0.09$ & $0.35 \pm 0.16$ \\
\hline Firing rate in wave $(\mathrm{Hz})$ & $2.99 \pm 0.07$ & $2.32 \pm 0.36$ & $3.32 \pm 0.43$ & $2.99 \pm 0.48$ \\
\hline Wave frequency (per min) & $0.86 \pm 0.06$ & $0.80 \pm 0.05$ & $0.78 \pm 0.06$ & $0.91 \pm 0.36$ \\
\hline Wave duration (s) & $9.66 \pm 0.92$ & $11.07 \pm 0.69$ & $12.09 \pm 2.05$ & $8.71 \pm 0.72^{* *}$ \\
\hline Wave size (\%) & $34.97 \pm 6.62$ & $24.75 \pm 1.04$ & $47.82 \pm 4.44$ & $21.89 \pm 6.12^{* * *}$ \\
\hline$\%$ spikes in burst & $72.37 \pm 33.83$ & $77.77 \pm 29.97$ & $81.32 \pm 27.79$ & $76.82 \pm 29.80^{*}$ \\
\hline Burst frequency (per min) & $0.67 \pm 0.39$ & $0.68 \pm 0.34$ & $0.81 \pm 0.92$ & $0.93 \pm 0.53^{*}$ \\
\hline Burst duration (s) & $1.27 \pm 0.83$ & $1.47 \pm 0.69^{*}$ & $2.16 \pm 1.03$ & $2.12 \pm 3.85$ \\
\hline Interburst interval (s) & $90.68 \pm 131.6$ & $92.84 \pm 85.33$ & $83.99 \pm 83.15$ & $73.33 \pm 92.87$ \\
\hline Interspike interval during burst (s) & $0.14 \pm 0.11$ & $0.17 \pm 0.12^{*}$ & $0.61 \pm 5.16$ & $0.64 \pm 3.64$ \\
\hline Firing rate in burst $(\mathrm{Hz})$ & $8.55 \pm 4.89$ & $7.08 \pm 3.81$ & $8.59 \pm 5.66$ & $7.13 \pm 4.50^{* * *}$ \\
\hline
\end{tabular}

${ }^{a}$ Data are mean \pm SD. Cholinergic retinal waves are smaller, with shorter wave duration and a lower firing rate per burst in SAC- $\beta 2$-cKO mice at P4 than in WT, but waves are more normal at P2 when Cre is expressed in a much smaller proportion of SACs.

${ }^{*} p<0.05 ;{ }^{* *} p<0.01 ;{ }^{* * *} p<0.001$.

firing rate and wave frequency were not significantly different (Fig. $1 \mathrm{I}, \mathrm{J}$; Student's $t$ test). At P2, when the conditional deletion of $\beta 2$-nAChRs from SACs is incomplete in $S A C-\beta 2-c K O$ mice (Fig. $1 B$ ), wave and spiking properties are not significantly different between $S A C-\beta 2-c K O s$ and WT controls (Fig. $1 J-O$; Table 1; Student's $t$ test). Measurements of wave properties at later ages are complicated by the emergence of the final, glutamatergic, retinal wave epoch (Stage III), which usually begins at $\sim \mathrm{P} 8$-P9 and continues until eye opening but is known to begin earlier in mice in which cholinergic waves are chronically disrupted (Blankenship et al., 2009; Ford and Feller, 2012). These results are consistent with models in which Stage II retinal waves propagate through a network of SACs that are interconnected via synapses expressing $\beta 2$-nAChRs, and that deleting these receptors from SACs truncates wave propagation and reduces wave size.

Spontaneous activity is desynchronized in SAC- $\beta 2-c K O$ mice ChAT-Cre-driven excision of $\beta 2$-nAChRs from SACs is not complete until $\sim \mathrm{P} 10$ in $S A C-\beta 2-c K O$ mice (Fig. $1 A, B$ ), $2-3 \mathrm{~d}$ after Stage II cholinergic waves normally transition to Stage III glutamatergic waves (Wong, 1999; Wong et al., 2000; Huberman et al., 2008; Blankenship et al., 2009; Blankenship and Feller, 2010). We extended the developmental time window during which retinal waves are mediated by cholinergic $\beta 2$-nAChRs by genetic deletion of the Type 1 vesicular glutamate transporter (Vglut1 or Slc17a7), which prevents the transition from Stage II to Stage III retinal waves (Blankenship et al., 2009). This allowed us to more comprehensively test the recurrent network model of Stage II cholinergic wave propagation and the consequences of SACspecific $\beta 2$ subunit elimination on visual circuit development. In SACs from P10-P11 mice lacking germline Vglut1 (VG1-KO) and conditionally heterozygous for $\beta 2$ (Vglut ${ }^{-/-} / \mathrm{ChAT}-\mathrm{Cre}^{+} /$ $\beta 2^{f l /+}$ : VG1-KO/ $\left.\beta 2 c H e t\right)$, DMPP (1 mM) elicited currents (77 \pm $17 \mathrm{pA}, n=23$; Fig. $2 A-C)$ that were comparable with those observed at P5-P6 in WT mice ( $86 \pm 60 \mathrm{pA}, n=18 ; p=0.66$, Student's $t$ test; Fig. $1 C$ ), consistent with previously published reports on the preservation of $\beta 2$-nAChR-mediated retinal waves

\section{$\leftarrow$}

(Figure legend continued.) size in SAC- $\beta 2-C K O$ s and WT controls at P4, with the distribution showing smaller wave sizes in $S A C-\beta 2$ - $K O$ retinas. $\boldsymbol{H}$, Average wave size (fraction of neurons active during a wave) in $S A C-\beta 2$-CKOs is much smaller than in WT controls. I, Overall mean firing rate (during the entire recording session) and wave frequency $(J)$ are similar in SAC- $\beta 2-C K O$ s and WT controls. $K$, STTC (a measurement of activity correlation between RGCs by distance; $L, M$ ) wave size, $(\boldsymbol{N})$ firing rate, and $(\boldsymbol{O})$ wave frequency were not significantly different between $C K O$ s and controls at $\mathrm{P} 2$. ${ }^{* * *} p<0.001$. in VG1-KO mice during the second week after birth (Blankenship et al., 2009). However, conditionally deleting $\beta 2$-nAChRs from SACs in mice that also lacked VG1 (Vglut ${ }^{-/-} / \mathrm{ChAT}_{-} \mathrm{Cre} \mathrm{C}^{+} /$ $\beta 2^{f l /-}$ : double knock-out [DKO]) significantly reduced DMPPinduced currents compared with control mice lacking only VG1 $(33 \pm 34 \mathrm{pA}$ in DKO mice, $n=23 ; 77 \pm 17 \mathrm{pA}$ in $V G 1-K O / \beta 2-$ cHet mice, $n=18 ; p=1.40 \times 10^{-6}$, Student's $t$ test; Fig. $2 B, C$ ). DMPP-elicited currents in P10-P11 SACs lacking both VG1 and $\beta 2$-nAChRs (DKO) were also much more variable compared with SAC- $\beta 2-c H e t$ control mice (95\% confidence interval of the SD significantly different between VG1-KO/ $\beta 2-c K O$ [26.2987, 46.8548] and VG1-KO/ $\beta 2$ - $c H e t$ controls [12.6934, 24.3784]; $p=$ $0.0028, F$ test; examples from multiple cells shown in Fig. $2 B$; quantification in Fig. $2 C$ ). This increased variability is consistent with the progressive Cre-mediated deletion of $\beta 2$-nAChRs from SACs in SAC- $\beta 2-c K O$ mice during the first 2 postnatal weeks.

Spontaneous retinal waves in vitro were similar in P8 and P11 VG1-KO mice (Fig. 2D,F,H,I), and retinal activity was blocked by the $\beta 2$-nAChRs antagonist $\mathrm{DH} \beta \mathrm{E}$ (Fig. $2 H$ ) but not the glutamate receptor antagonists NBQX+APV (Fig. $2 \mathrm{H}$; P11 VG1-KO Ringer's firing rate mean $=0.606 \pm 0.372 \mathrm{~Hz}, n=8 ; \mathrm{VG} 1-\mathrm{KO}$ $\mathrm{DH} \beta \mathrm{E}$ mean $=0.006 \pm 0.007, n=4 ; p=0.003$, Student's $t$ test) (Blankenship et al., 2009), further confirming the cholinergic origin of spontaneous activity in second week VG1-KO mice. However, the progressive deletion of $\beta 2$-nAChRs from SACs dramatically disrupted activity correlations in neighboring RGCs at P8 (Fig. 2E,I; Table 2) and especially P11 (Fig. 2G,I; Table 2) in mice lacking both VG1 and $\beta 2$-nAChRs (DKO), implying that double knock-out largely eliminated compensatory cholinergic activity.

\section{Spontaneous activity in SACs and neighboring RGCs is desynchronized in SAC- $\beta 2-c K O$ mice}

We performed paired patch-clamp recordings in SACs and RGCs at P10 in $S A C-\beta 2-c K O$ mice to examine the specific role of $\beta 2$-nAChRs in SACs in correlating activity between neighboring retinal neurons. During the first postnatal week, SACs in WT mice depolarize autonomously, acting as semipacemakers that initiate spontaneous waves (Zheng et al., 2006; Ford et al., 2012). In VG1-KO mice, these autonomous depolarizations persist into the second postnatal week, triggering acetylcholine release and generating regular wave activity across the RGC population. In $\beta 2$ control mice ( VG1-KO/ $\beta 2$ WT), EPSCs in RGCs occurred at regular intervals and were synchronized with spontaneous depolarizations in neighboring SACs (Fig. $3 B, E$ ). However, in SACs from DKO mice 


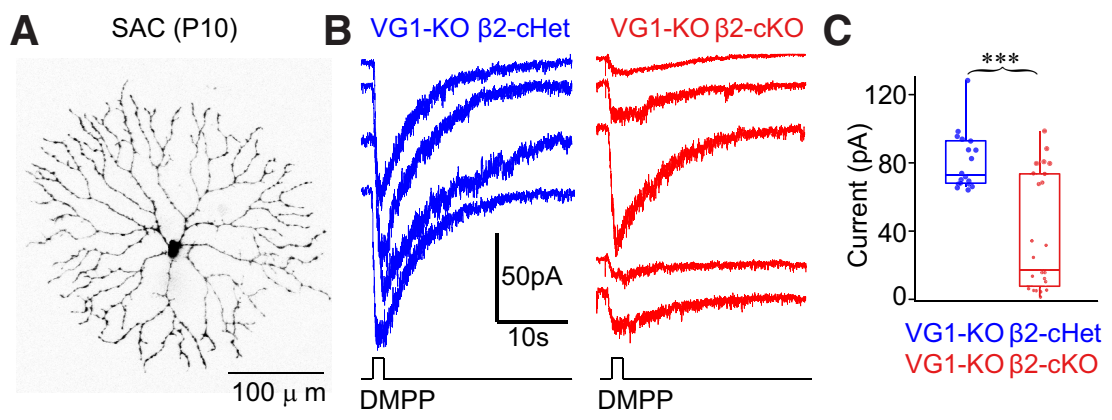

D VG1-KO $\beta 2-\mathrm{cHet}(\mathrm{P} 8)$

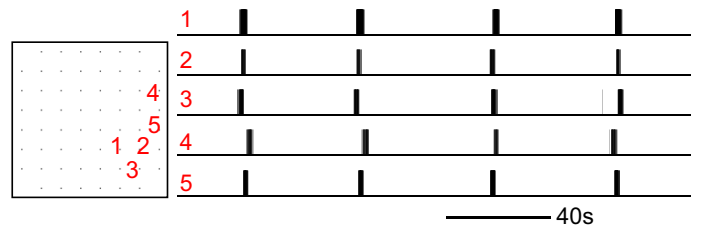

E VG1-KOß2-cKO (P8)

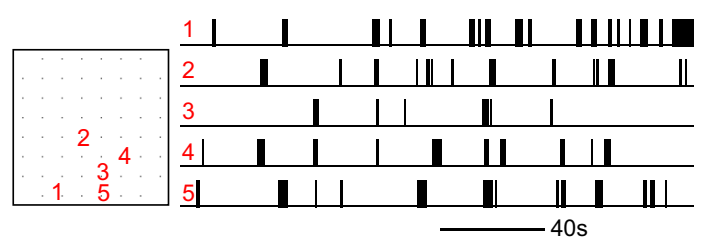

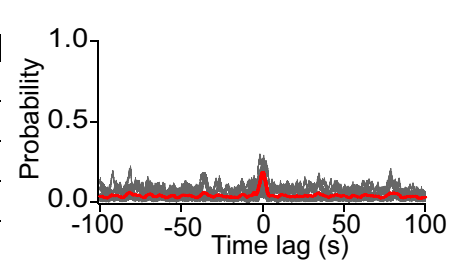

F VG1-KOß2-cHet (P11)
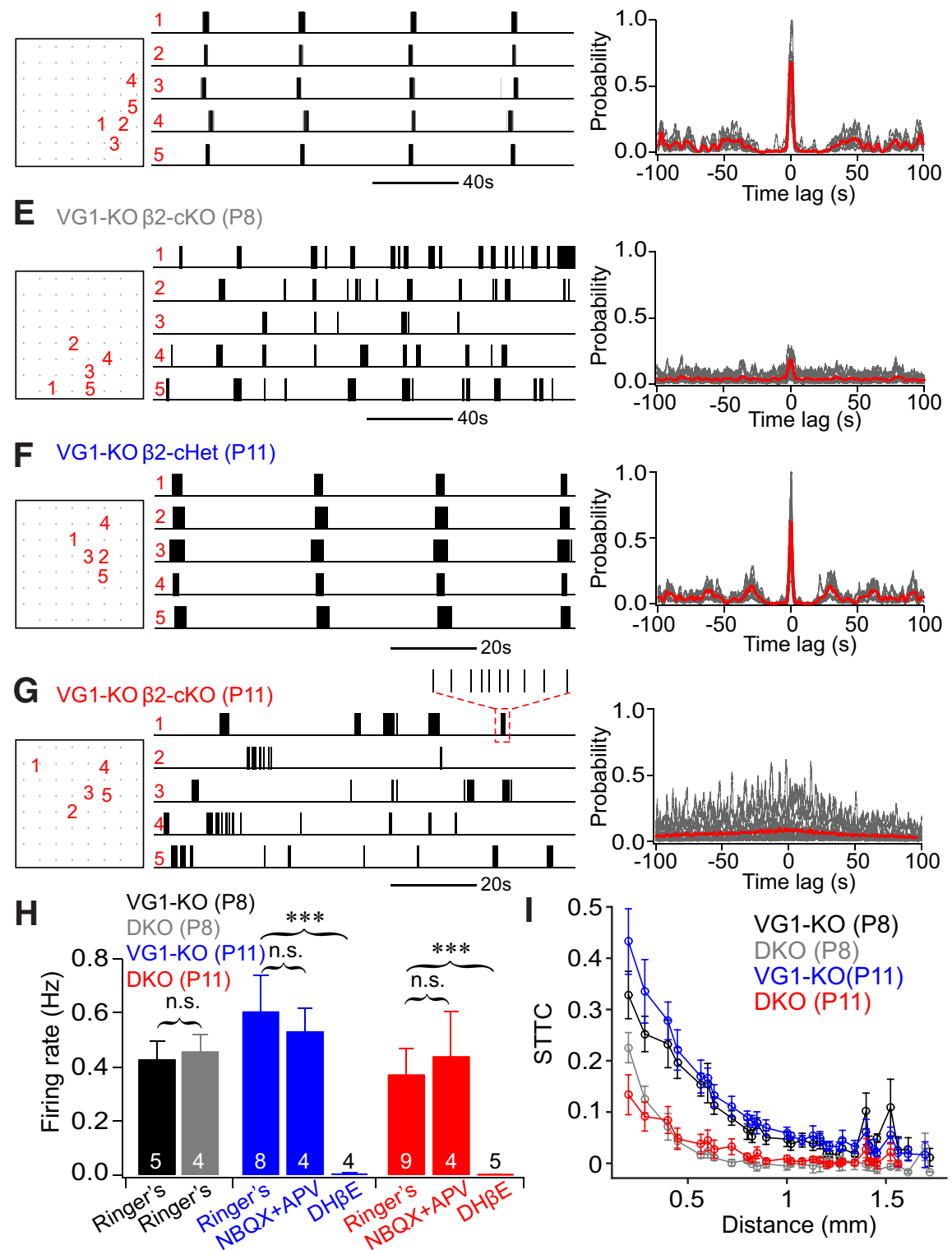

Figure 2. RGC spontaneous activity was desynchronized in mice with germline deletion of Vglut 1 and conditional deletion of $\beta 2$ from SACs (VG1-KO $\beta 2$-cKO). A, Morphology of a SAC filled with AlexaFluor-555 after whole-cell recording. $\boldsymbol{B}$, Example excitatory currents elicited by puff application of DMPP (1 mM) on P11 SACs in VG1 ${ }^{-/-} /$ChAT-Cre $e^{+} / \beta 2^{\mathrm{fl} /+}$ (VG1-KO $\beta 2-$-CHet, left) and VG1 ${ }^{-/-} / \mathrm{ChAT}^{-} \mathrm{Cre}^{+} / \beta 2^{\mathrm{fl} /-}$ (VG1-KO $\beta 2-\mathrm{CKO}$, right) mice. C, Summary quantification of $\boldsymbol{B}$. Amplitudes of DMPPinduced currents are much smaller and more variable in $\beta 2$-deficient SACs. D-G, Example spontaneous spiking activity (left) and cross-correlation (right) of five neighboring $\mathrm{RGCs}$ recorded from retinas with either one $(\boldsymbol{D}, \boldsymbol{F})$ or two copies $(\boldsymbol{E}, \boldsymbol{G})$ of $\beta 2$ deleted from SACs. All mice are Vglut 1 knock-out background, and recordings were made at either $P 8(\boldsymbol{D}, \boldsymbol{E})$ or $\mathrm{P} 11(\boldsymbol{F}, \boldsymbol{G})$. RGC spontaneous activity was highly correlated in $\beta 2$-cHet retina at $P 8$ and $P 11(\boldsymbol{D}, \boldsymbol{F}$, respectively) but was significantly reduced in $S A C-\beta 2-c K O$ retina $(\boldsymbol{E}, \boldsymbol{G}$, respectively). $\boldsymbol{H}$, The average firing rate of RGCs recorded from the four groups of mice shown in $\boldsymbol{D}-\boldsymbol{G}$. Firing rate is comparable between $\beta 2$ heterozygous and SAC- $\beta 2$-cKOs at $P 8$. The firing rate of $S A C-\beta 2-c K O$ s is slightly reduced at $P 11$ but is not significantly different from $\beta 2$-cHet controls: $p=0.22$ (Student's $t$ test). RGC spontaneous spiking activity in VG1-KO mice was
( VG1-KO/ $\beta 2-c K O)$, spontaneous depolarizations occur irregularly, and EPSCs in nearby RGCs were also irregular and variable in amplitude (Fig. 3C,E; $p<$ 0.001 when comparing between SACs in $V G 1-K O / \beta 2-c K O$ and $V G 1-K O / \beta 2-$ $c H e t ; p<0.001$ between RGCs in VG1$\mathrm{KO} / \beta 2-c K O$ and $V G 1-K O / \beta 2-c H e t, \mathrm{~K}-\mathrm{S}$ tests). Some of the EPSCs in RGCs were correlated with activity in the neighboring patched SAC, but most of the small EPSCs were not synchronized with spontaneous SAC activity, resulting in a significant reduction in the Pearson correlation between paired SACs and RGCs (Fig. $3 B, C, F ; p<0.05$ for all thresholds, Student's $t$ test). These results suggest that RGCs in DKO mice receive synaptic input from multiple SACs that are not correlated with one another, in contrast to WT RGCs that demonstrate few spikes outside of correlated SAC activity. To determine whether the spiking activity in RGCs was evoked by irregular synaptic inputs from SACs, we performed loose-patch recordings from RGCs and whole-cell patch-clamp recording from neighboring SACs simultaneously (Fig. 3D). RGCs fire bursts of spiking activity with varying interburst intervals. Although most bursting activity in RGCs was synchronized with spontaneous depolarizations of the simultaneously measured SAC in DKO mice, some RGC activity occurred in the absence of depolarization in the SAC, also suggesting that RGCs received synaptic input from multiple SACs that were not well synchronized with each other in $S A C-\beta 2$ cKO mice. Moreover, while synaptic transmission among SACs was significantly weakened in $S A C-\beta 2-c K O$ mice (Fig. $1 A-C)$, currents elicited by puff application of DMPP onto RGCs were unchanged in $S A C-\beta 2-c K O$ mice relative to controls $(134 \pm 20 \mathrm{pA}$ in $S A C$ $\beta 2-c K O$ RGCs, $n=10$ cells, and $177 \pm$ $16 \mathrm{pA}$ in $S A C-\beta 2-c H e t$ control RGCs, $n=12$ cells, $p=0.12$, Student's $t$ test). This implies that $\beta 2$-nAChR-mediated synaptic neurotransmission was specifically disrupted among the network of

\section{$\leftarrow$}

blocked by $\mathrm{DH} \beta \mathrm{E}$ at $\mathrm{P} 11$ but was unaffected by the addition of glutamate receptor antagonists NBQX and APV. I, RGC correlations (STTC) from the four groups of mice shown in $\boldsymbol{D}-\boldsymbol{F}$. In $\beta 2$-CHet mice, the correlation of spontaneous RGC activity was similar at P8 and P11. In $\beta 2$-cKOs, correlations were reduced significantly at P8 compared with $\beta 2$-chet controls, and there is almost no correlation of RGC activity at P11. n.s., Not significant. ${ }^{* * *} p<0.001$. 
Table 2. Properties of spontaneous retinal activity in SAC- $\beta 2-c K O$ mice on VG1-KO background $^{a}$

\begin{tabular}{|c|c|c|c|c|}
\hline & Contr P8 $(n=5)$ & DKO P8 $(n=4)$ & Contr P11 $(n=8)$ & DK0 P11 $(n=9)$ \\
\hline Firing rate $(\mathrm{Hz})$ & $0.46 \pm 0.14$ & $0.43 \pm 0.12$ & $0.61 \pm 0.37$ & $0.31 \pm 0.32$ \\
\hline Firing rate in wave $(\mathrm{Hz})$ & $3.95 \pm 0.81$ & $3.85 \pm 0.15$ & $3.92 \pm 1.32$ & NA \\
\hline Wave frequency (per min) & $0.97 \pm 0.37$ & $1.55 \pm 0.41$ & $1.26 \pm 0.33$ & NA \\
\hline Wave duration (s) & $5.24 \pm 0.45$ & $9.18 \pm 2.18^{* *}$ & $8.06 \pm 1.28$ & NA \\
\hline Wave size (\%) & $48.06 \pm 4.39$ & $21.98 \pm 4.62^{* * *}$ & $50.13 \pm 10.82$ & NA \\
\hline$\%$ spikes in burst & $87.25 \pm 19.20$ & $85.90 \pm 15.13$ & $87.11 \pm 18.39$ & $81.48 \pm 15.48^{* * *}$ \\
\hline Burst frequency (per min) & $1.05 \pm 0.50$ & $1.31 \pm 0.74^{* * *}$ & $1.27 \pm 0.65$ & $1.02 \pm 1.14^{* * *}$ \\
\hline Burst duration (s) & $2.70 \pm 16.22$ & $2.70 \pm 16.22$ & $2.31 \pm 12.7$ & $8.61 \pm 25.75^{* * *}$ \\
\hline Interburst interval (s) & $62.69 \pm 42.66$ & $65.07 \pm 71.13$ & $63.91 \pm 79.01$ & $116.4 \pm 146.7^{* * *}$ \\
\hline Interspike interval during burst (s) & $0.31 \pm 2.19$ & $0.41 \pm 1.98$ & $0.28 \pm 1.79$ & $0.78 \pm 3.43^{* * *}$ \\
\hline Firing rate in burst (Hz) & $14.34 \pm 8.93$ & $15.32 \pm 8.22^{* * *}$ & $17.24 \pm 10.49$ & $10.76 \pm 5.83^{* * *}$ \\
\hline
\end{tabular}

${ }^{a}$ Data are mean \pm SD. NA, Not applicable. Retinal activity mimics cholinergic waves in VG1 ${ }^{-/-}$controls at P8 and P11, but SAC- $\beta 2-$ - KO mice on the VG1 ${ }^{-/-}$background significantly disrupt second week retinal wave duration, size, burst frequency, and firing rate at $\mathrm{P} 8$, and drastically disrupt waves at $\mathrm{P} 11$.

${ }^{* *} p<0.01 ;{ }^{* * *} p<0.001$.

SACs in SAC- $\beta 2-c K O$ mice, whereas cholinergic neurotransmission was maintained on RGCs.

We also examined spontaneous retinal waves by imaging in vivo during the first (P6-P7) and the second (P10-P11) postnatal weeks in VG1-KO, $\beta 2$-control ( VG1-KO/ $\beta 2-c H e t)$, and DKO ( $V G 1-K O / \beta 2-c K O)$ mice. Retinal waves were imaged in topographically mapped RGC axon arbors in the SC by loading RGCs with a genetically encoded (GCaMP6) fluorescent calcium indicator and imaging their activity in the SC (Fig. 4). The in vivo properties of retinal waves in wild-type and several mutant mouse strains have been previously characterized using this approach, with differences in mutant wave frequency and spatiotemporal properties being reported between in vitro and in vivo recording conditions (Ackman et al., 2012; Burbridge et al., 2014; $\mathrm{Xu}$ et al., 2015). In vitro, VG1-KO mice lack Stage III (glutamatemediated) retinal waves, and spontaneous retinal activity is mediated by nAChRs through the first 2 postnatal weeks (Blankenship et al., 2009). In vivo, retinal wave activity in VG1-KO mice was eliminated by intraocular injections of epibatidine, a $\beta 2-n A C h R$ specific agonist at both P6-P7 and P10-P11 (data not shown). In $\beta 2$ control mice ( $V G 1-K O / \beta 2-\mathrm{WT}$ ), spontaneous activity occurred periodically and propagated across the SC in a well-defined wave front at both P6-P7 (Fig. 4F-I) and P10-P11 (Fig. 4B, F-I). In double-mutant mice, spontaneous RGC activity does occur at a regular frequency in vivo at these ages (Fig. 4F; P10 $\beta 2$ control ROI activation frequency $=0.013 \pm 0.002 \mathrm{~Hz}$, $n=12$ movies in three SC hemispheres; P10 DKO frequency $=$ $0.013 \pm 0.003 \mathrm{~Hz}, n=12$ movies in five SC hemispheres; $p=$ 0.53 , Student's $t$ test). Although the duration of calcium activity was comparable between DKOs and $\beta 2$ controls (Fig. 4G; P10 $\beta 2$ control ROI activation duration $=2.18 \pm 0.52 \mathrm{~s}, n=12$ movies in three SC hemispheres; P10 DKO duration $=1.95 \pm 0.52 \mathrm{~s}, n=$ 12 movies in five SC hemispheres; $p=0.30$, Student's $t$ test), most activity was restricted in extent and lacked an obvious propagating wave front at P10-P11. Correspondingly, the size of the synchronous spontaneous retinal activity domains (coverage area) at P10-P11 in DKOs was much smaller compared with $\beta 2$ controls (Fig. $4 H$; mean $=20.4 \pm 2.32 \mu \mathrm{m}^{2}\left(\times 10^{4}\right)$ for DKOs vs $57.9 \pm$ $6.49 \mu \mathrm{m}^{2}\left(\times 10^{4}\right)$ for controls, $p=9.32 \times 10^{-5}$ Student's $t$ test; and Figure $4 I ; p<0.001$, K-S test for cumulative distribution). Interestingly, overall spontaneous activity was also more frequent in DKOs than in $\beta 2$ controls at P6-P7 (P6-P7 $\beta 2$ control ROI activation frequency $=0.011 \pm 0.003 \mathrm{~Hz}, n=12$ movies in three SC hemispheres, P6-P7 DKO frequency $=0.017 \pm 0.004 \mathrm{~Hz}, n=$ 12 movies in five hemispheres, $p=0.003$, Student's $t$ test), further suggesting that preventing cholinergic neurotransmission in a subset of SACs disrupted the spatiotemporal properties of spontaneous retinal activity. However, the amplitudes of the calcium transients observed in the SC were not significantly different between DKOs and $\beta 2$ control mice at both ages (data not shown), which is consistent with the comparable firing rates observed in RGCs in vitro with a multielectrode array (Fig. $2 H$ ).

\section{Eye-specific segregation in the dLGN and SC is disrupted in $S A C-\beta 2-c K O$ mice at $\mathbf{P 8}$}

Whole-animal $\beta 2$-nAChR $\mathrm{KO}$ mice and mice that lack $\beta 2$ nAChRs across some or all layers of the retina have disordered spontaneous retinal waves and disrupted eye-specific segregation (Stellwagen and Shatz, 2002; McLaughlin et al., 2003; Torborg et al., 2005; Huberman et al., 2008; Feller, 2009; Stafford et al., 2009; $\mathrm{Xu}$ et al., 2011; Burbridge et al., 2014). However, the specific necessity of $\beta 2$-nAChRs in SACs for eye-specific segregation is unknown. In $S A C-\beta 2-c K O$ mice, wave propagation is truncated during the first postnatal week due to the gradual elimination of $\beta 2$-nAChRs from SACs (Fig. 1; Tables 1,2 ). We examined eyespecific RGC projections to both the dLGN and the SC in SAC$\beta 2-c K O$ mice at the end of the first postnatal week (P8), when eye segregation is nearly complete. Deletion of $\beta 2-\mathrm{nAChRs}$ from a subset of SACs in SAC- $\beta 2-c K O$ mice increased the overlap of projections to the dLGN from the two eyes and decreased the Segregation index compared with littermate controls (Fig. 5A-C; $S A C-\beta 2-c H e t$ and Het combined in Fig. $5 B, C, E, F$; P8 WT Segregation index $=1.06 \pm 0.07, n=4 ; S A C-\beta 2-c K O$ Segregation index $=0.89 \pm 0.13, n=6$; combined Het Segregation index $=$ $1.00 \pm 0.09, n=11$; WT- SAC- $\beta 2-c K O p=0.035$; Het- $S A C-\beta 2-$ $c K O p=0.082$, WT-Het $p=0.576$, ANOVA and Tukey's HSD) (Fig. $5 A-C$ ). RGC projections to the SC were also perturbed in $S A C-\beta 2-c K O$ mice. RGC axons from the contralateral eye normally project to the most superficial layer, the SGS layer of the SC, whereas axons from the ipsilateral eye project to the stratum opticum layer just below the SGS (Fig. 5D). However, in P8 SAC$\beta 2-c K O$ mice, there was significantly greater overlap of the ipsilateral and contralateral eye RGC projections to the SGS layer relative to littermate controls (Fig. $5 D-F$; P8 WT overlap = $0.04 \pm 0.02, n=5 ;$ SAC- $\beta 2-c K O$ overlap $=0.19 \pm 0.18, n=5$; combined Het overlap $=0.06 \pm 0.03, n=9$; WT- SAC- $\beta 2-c K O$ $p=0.037$; Het- SAC- $\beta 2-c K O p=0.046$, WT-Het $p=0.883$, ANOVA and Tukey's HSD). These results suggest that the gradual but specific deletion of $\beta 2-n A C h R s$ from SACs in SAC- $\beta 2$ cKO mice disrupts spontaneous retinal waves and that this disruption in turn interferes with the process of eye-specific segregation in the dLGN and SC at P8. 

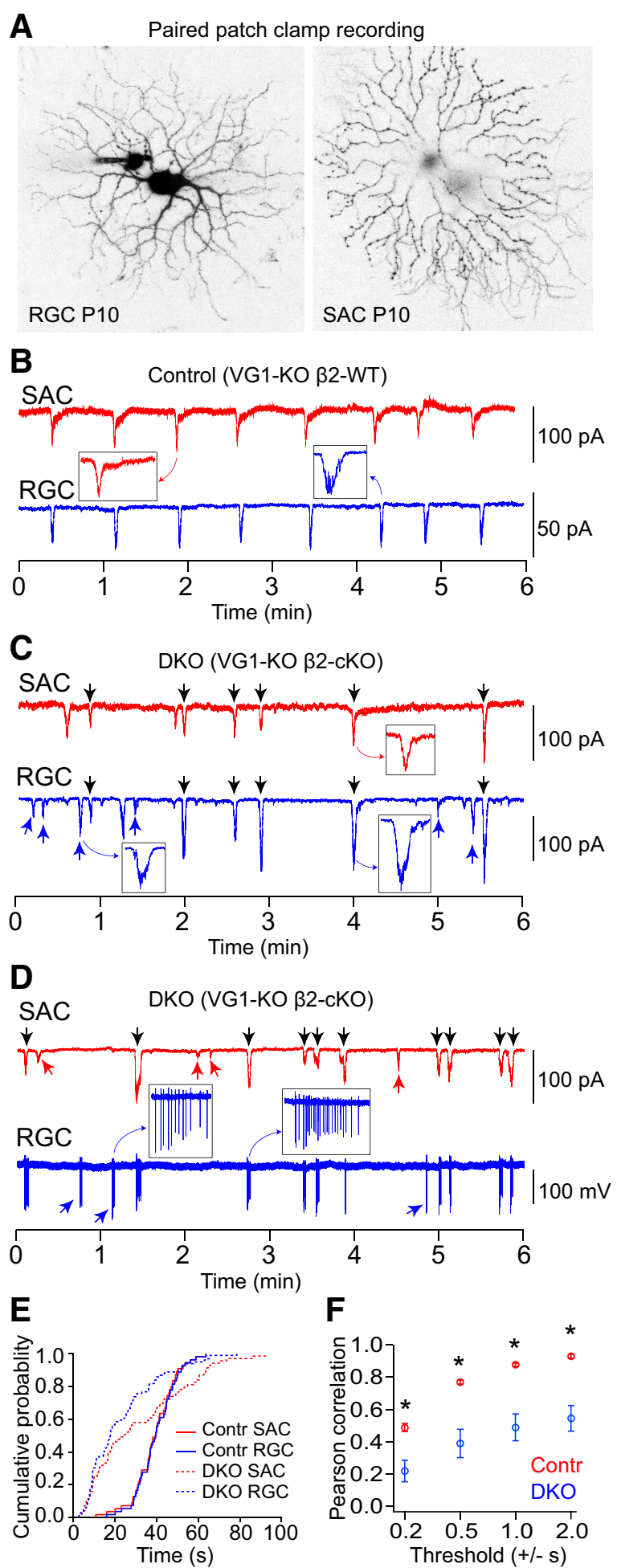

Figure 3. Spontaneous activity in RGCS and neighboring SACs was desynchronized in VG1$K 0 / \beta 2-C K O$ s at P10. A, Representative morphologies of a RGC and a SAC filled with AlexaFluor488 and AlexaFluor-555, respectively, after paired patch-clamp recording. $\boldsymbol{B}$, EPSCs recorded from a SAC and a neighboring RGC simultaneously in a VG1-KO/ $\beta 2$-cHet mouse at P10.C, EPSCS recorded from a $S A C$ and a neighboring $R G C$ simultaneously in a VG1-KO/ $\beta 2-c K O$ mouse at P10. Spontaneous EPSCs were highly correlated between the SAC and RGC in the VG1-KO/ $\beta 2$-cHet mice but were desynchronized in the VG1-KO/ $\beta 2-c K O$ mouse at P10. D, Paired recording of EPSCs in a SAC (whole-cell mode) and spiking activity in a RGC (cell-attached mode) from the retina of a VG1-KO/ $\beta 2$-CKO mouse at P10. C, D, Black arrows indicate synchronized events. Red and blue arrows indicate events that are not synchronized. $\boldsymbol{E}$, Cumulative distribution of interevent intervals in SACs (red) and RGCs (blue) in VG1-KO/ $\beta 2$-cHet and VG1-KO/ $\beta 2$-cKO mice at P10. There was a wider distribution of interevent intervals in the VG1-KO/ $\beta 2-c K O$ mouse
Eye-specific segregation in VG1-KO mice is normal

Late-stage retinal waves are thought to contribute to the maintenance and refinement of eye-specific circuits before eye opening (Chapman, 2000; Xu et al., 2010). We were curious whether eye-specific segregation was impacted by the absence of Stage III retinal waves in VG1-KO mice (Blankenship et al., 2009). At P8, around the time that cholinergic Stage II waves normally transition to glutamatergic Stage III waves (Blankenship et al., 2009), and at P15, around the time of eye opening, the overlap of ipsilateral RGC axons with contralateral axons in the dLGN and the Segregation index were no different in $V G 1-K O$ and littermate control mice (Fig. 6B, D; P8 VG1-WT overlap $=9.9 \pm 1.3 \%, n=10 ;$ P8 VG1-KO overlap $=11.4 \pm$ $1.3 \%, n=6 ; p=0.052$, Student's $t$ test; P15 VG1-WT overlap $=7.8 \pm 1.2 \%, n=14 ; \mathrm{P} 15$ VG1-KO overlap $=8.8 \pm 1.2 \%$, $n=8 ; p=0.09$, Student's $t$ test; P8 VG1-WT Segregation index $=0.93 \pm 0.04, n=10$; P8 VG1-KO Segregation index $=$ $0.87 \pm 0.04, n=6 ; p=0.07$, Student's $t$ test; P15 VG1-WT Segregation index $=1.01 \pm 0.08, n=14$; P15 VG1-KO Segregation index $=0.99 \pm 0.1 \%, n=8 ; p=0.66$, Student's $t$ test). In the SC, the fraction of ipsilateral axons in the SGS and the Segregation index were also no different at both $\mathrm{P} 8$ and $\mathrm{P} 15$ in $V G 1-K O$ relative to littermate control mice (Fig. $6 A, C$; P8 VG1-WT \% ipsilateral in SGS $=3.7 \pm 2.9 \%, n=10$; P8 VG1-KO \% ipsilateral $=3.4 \pm 2.0 \%, n=6 ; p=0.82$, Student's $t$ test; P15 VG1-WT \% ipsilateral $=1.4 \pm 0.7 \%, n=$ 14; P15 VG1-KO \% ipsilateral $=1.1 \pm 0.5 \%, n=8 ; p=0.22$, Student's $t$ test; P8 VG1-WT overlap $=3.7 \pm 2.9, n=10$; P8 $V G 1-K O$ overlap $=3.4 \pm 2.0, n=6 ; p=0.81$, Student's $t$ test; P15 VG1-WT overlap $=1.4 \pm 0.7, n=14$; P15 VG1-KO overlap $=1.1 \pm 0.6 \%, n=8 ; p=0.90$, Student's $t$ test $)$. These data reveal that Stage III waves are not required for normal segregation of axons from the two eyes in the dLGN and SC, and suggest that the persistence of Stage II retinal waves until eye opening is sufficient to mediate normal segregation.

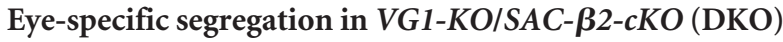 mice is disrupted}

Our results indicate that the spatial propagation of spontaneous activity in RGCs during the first week after birth is closely associated with the pattern of activity in the underlying network of mutually connected SACs and that glutamate waves during the second postnatal week are unnecessary for the emergence of normal eye-specific segregation. We next explored the consequences of uncoupling SAC mutual connectivity on the development of retinogeniculate and retinocollicular projections when glutamatergic (Stage III) waves are also eliminated. In these experiments (Fig. 7), we examined eye-specific segregation in the dLGN and SC in SAC- $\beta 2-c K O$ compared with $\beta 2$ control mice, all on a VG1-KO background. Deletion of $\beta 2$-nAChRs from SACs in DKO mice disrupted eye-specific segregation and significantly enlarged projections from the ipsilateral eye to the dLGN at both P8 and at P15 (Fig. $7 A, C, D)$ compared with $\beta 2$ control mice (VG1-KO/ $\beta 2$-WT or $V G 1-K O / \beta 2-c H e t ; \mathrm{P} 8$ VG1-KO overlap $=11.1 \pm 1.3 \%, n=6$; P8 DKO overlap $=13.5 \pm 2.1 \%, n=9 ; p=0.04$, Student's $t$ test; P15 VG1-KO overlap $=8.75 \pm 1.2 \%, n=8$; P15 DKO

(dashed lines). $\boldsymbol{F}$, Pearson correlation between RGCS and SACs in the VG1-KO/ $\beta 2-c K O$ s was significantly lower than in the VG1-KO/ $\beta 2$-chet controls at all thresholds. ${ }^{*} p<0.05$ (Student's $t$ test). 

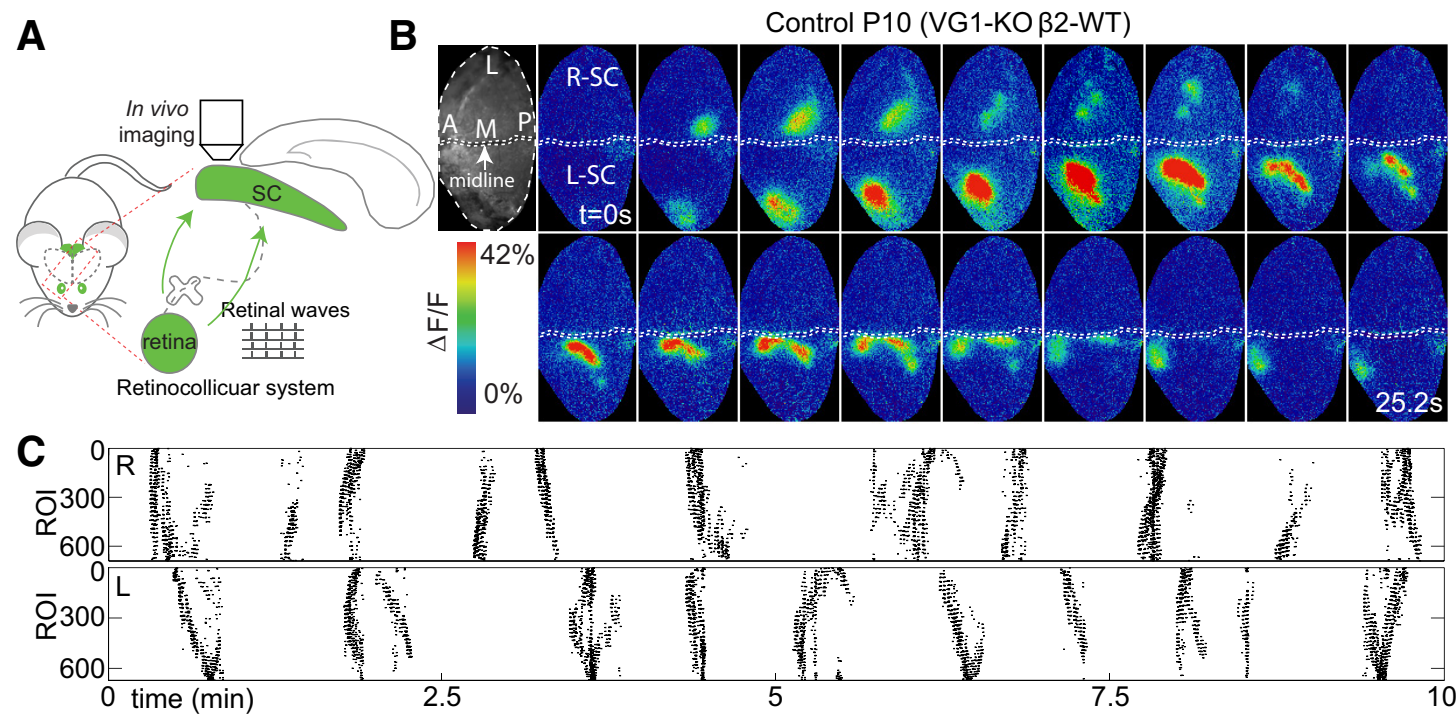

D

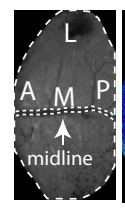

B

E
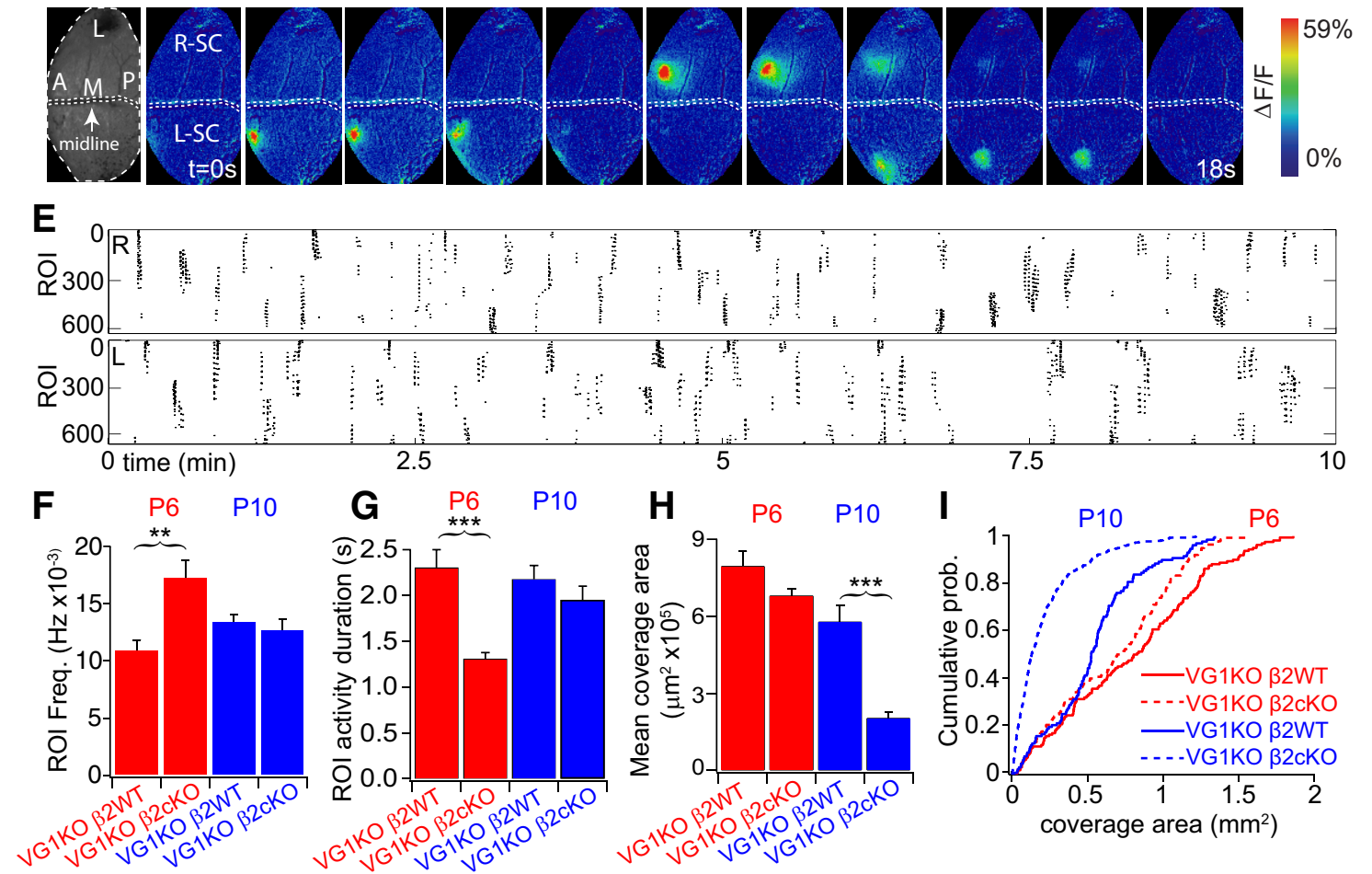

DKO P10 (VG1-KO $\beta 2-c K O)$
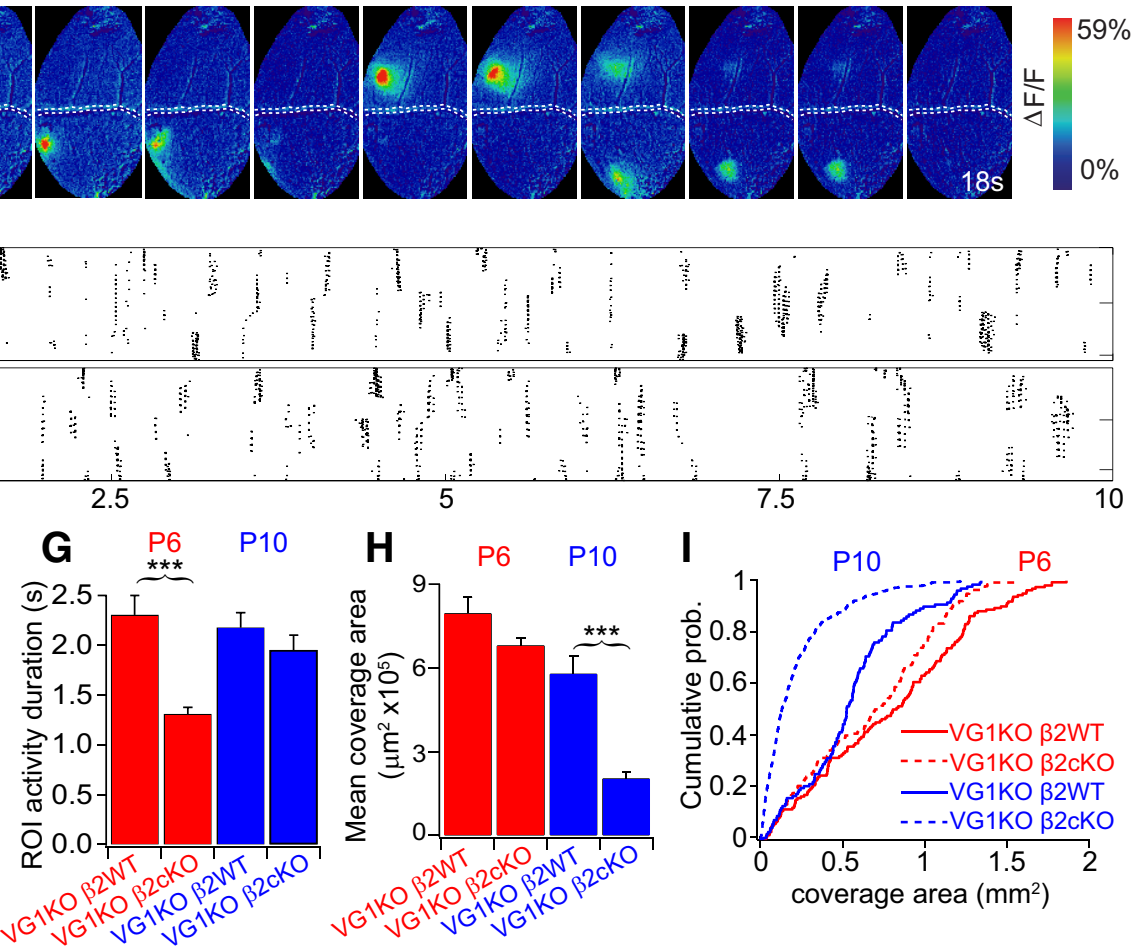

Figure 4. Truncated wave activity in vivo in VG1-KO/ $\beta 2-c K 0$ at P10. A, Retinal wave-imaging schematic. Retinal waves were imaged in vivo in topographically mapped axon arbors of RGCs in the upper layers of the $\mathrm{SC}$ through a craniotomy. Calcium activity in RGC axons in the $\mathrm{SC}$ was measured through viral expression of GCaMP6 in RGCs. $B$, Example of two wave montages from two hemispheres of a P10 $\beta 2$-control mouse that lacks Vglut1 (VG1 ${ }^{-/-} / C_{\text {CAT-Cre }}-/ \beta 2^{\mathrm{fl} /+}$ ). Top, Grayscale images (left) represent the craniotomy over the SC. L, Lateral; M, medial; A, anterior; P, posterior (for this and all in vivo image figures). White arrowheads indicate onsets of waves in the right and left SC hemispheres (R-SC and L-SC, respectively). Arrows indicate propagation of retinal wave fronts. A clear, slowly propagating wave front was typical in heterozygous mice. Movie frames shown in montage at $1.6 \mathrm{~s}$ interval. All movies were acquired at $5 \mathrm{~Hz}$. $C$, Raster plot of $10 \mathrm{~min}$ recordings from the same mouse. Each row in the raster corresponds to one $10 \times 10 \mu \mathrm{m} \mathrm{ROl} \mathrm{in} \mathrm{the} \mathrm{indicated} \mathrm{hemisphere.} D$, Example of three wave montages from a P10 SAC- $\beta 2$ - $c K 0$ mouse that also lacks Vglut1 (VG1 ${ }^{-1-} / C_{C A T-C r e} / \beta 2^{\mathrm{f} /-}$ : DKO). White arrowheads indicate onsets of spontaneous retinal activity. There was no clear propagating wave front in the DKO mouse; rather, correlated activity bursts repeatedly and synchronously activated small areas of the SC. Top, Grayscale images (left) represent craniotomies over SC. Movies were acquired at $5 \mathrm{~Hz}$, and frames in montage are at $1.8 \mathrm{~s}$ intervals. Scale bars, $200 \mu \mathrm{m}$. $\boldsymbol{E}$, Raster plot of $10 \mathrm{~min}$ recordings from the mouse shown in $\boldsymbol{D}$. Each row in the raster corresponds to one $10 \times 10 \mu \mathrm{m}$ ROI in the indicated hemisphere. $\boldsymbol{F}$, There was a significant increase in the frequency of synchronous spontaneous activity in a given ROI in DKOs at P6. However, spontaneous activity in a given ROI occurred at a similar frequency in DKO mice at P10 compared with VG1-KO/ $\beta 2$-WT controls. G, Activity duration was significantly smaller in the DKOs at P6 but similar at P10 compared with VG1-KO/ $\beta 2$-WT controls. Mean wave size $(\boldsymbol{H})$ and cumulative distribution of wave sizes (I) in VG1-KO/ $\beta 2$-cKOs and VG1-KO/ $\beta 2-W T$ controls at P6 and P10. Wave size was significantly reduced in the DKOs at P10. ${ }^{* *} p<0.01 ;{ }^{* * *} p<0.001$.

overlap $=11.3 \pm 1.1 \%, n=5 ; p=0.004$, Student's $t$ test; P8 VG1-KO Segregation index $=0.87 \pm 0.04, n=10$; P8 DKO Segregation index $=0.79 \pm 0.09, n=6 ; p=0.02$, Student's $t$ test; P15 VG1-KO Segregation index $=0.99 \pm 0.1, n=14 ; \mathrm{P} 15$
DKO Segregation index $=0.83 \pm 0.07 \%, n=8 ; p=0.01$, Student's $t$ test). This indicates that interfering with the propagation of $\beta 2$-nAChR-mediated retinal waves in $S A C-\beta 2-c K O$ mice caused the persistent disruption of eye-specific segrega- 
A
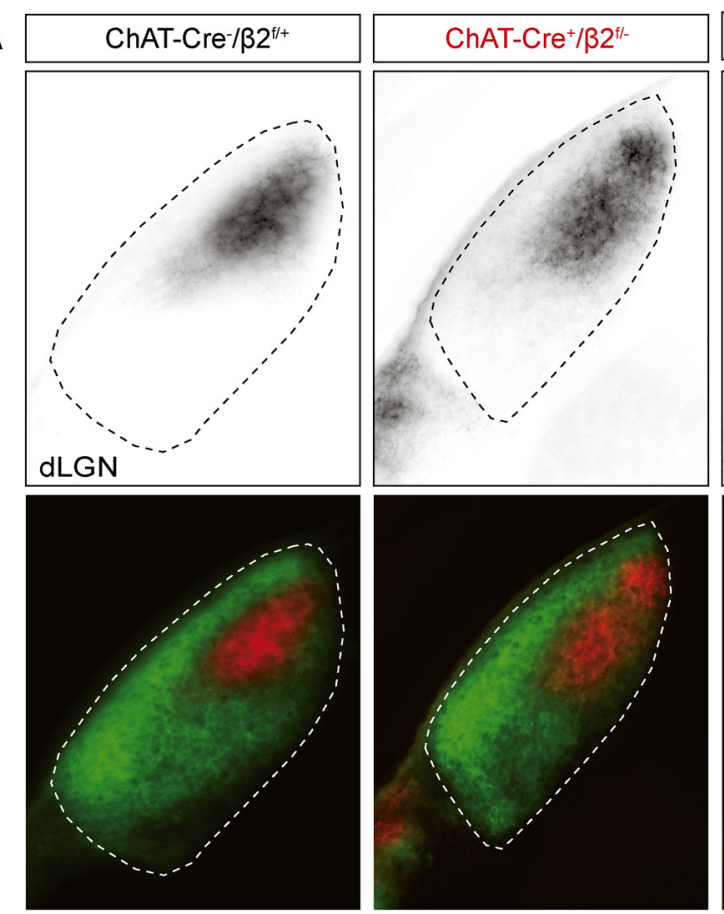

D
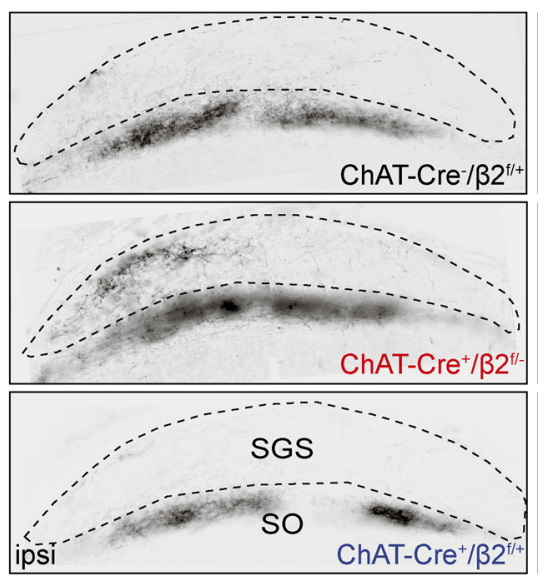
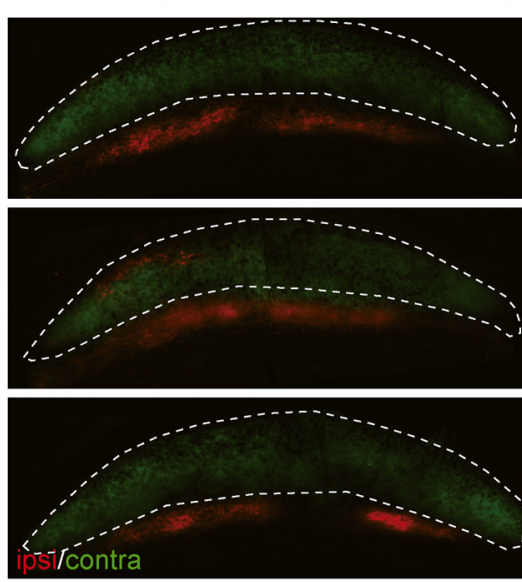
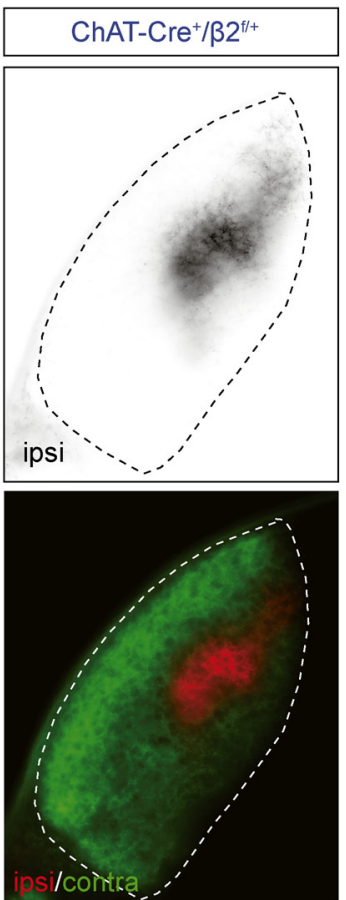

\section{C}

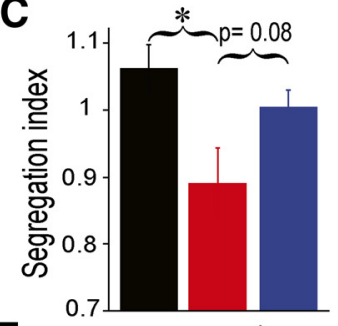

E
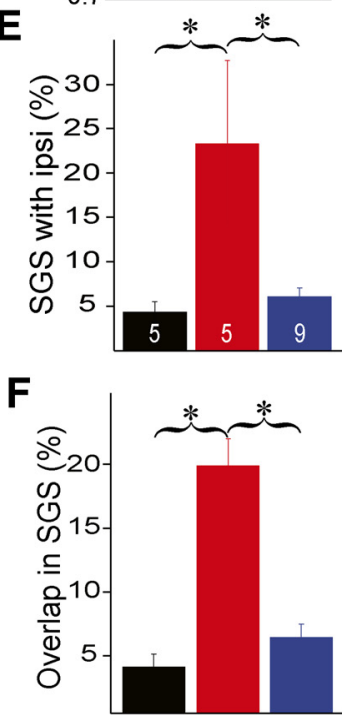

Figure 5. Eye-specific segregation is disrupted in the SAC- $\beta 2-c K O$ s at P8. Whole eye (vitreal) injection of Alexa-conjugated cholera toxin dye bulk labels most RGC axon projections in the dLGN $(\boldsymbol{A}-\boldsymbol{C})$ and the SC (D-F). A, Example dLGN (coronal sections) of WT (ChAT-Cre ${ }^{-} / \beta 2^{\mathrm{fl} /+}$ ) and $\beta 2$ heterozygous controls (ChAT-Cre $/ \beta 2^{\mathrm{fl} /+} ;$ SAC- $\beta 2$ - -CHet and ChAT-Cre $/ \beta 2^{\mathrm{fl} /-}$; Het; Combined in $\boldsymbol{B}, \boldsymbol{C}, \boldsymbol{E}, \boldsymbol{F})$. RGC projections from the contralateral eye (green) and the ipsilateral eye (red). $\boldsymbol{B}$, Summary histogram showing the percentage of dLGN area with overlapped contralateral and ipsilateral projections. In SAC- $\beta 2-\mathrm{CKOS}\left(\mathrm{ChAT}-\mathrm{Cre}^{+} / \beta 2^{\mathrm{fl} / \mathrm{fl}}\right)$, ipsilateral eye projections were expanded and intermingled with projections from the contralateral eye, resulting in a greater overlap relative to controls. C, Summary histogram showing segregation of contralateral and ipsilateral projections (Segregation index) in dLGN. Segregation index was reduced in SAC- $\beta 2-c K 0$ s relative to controls (SAC- $\beta 2$-CHet and Het controls combined). D, Example retinocollicular projections from WT, $\beta 2$ heterozygous controls, and SAC- $\beta 2$ - $-K O$ mice. Contralateral axons (green) project to the most superficial (SGS) layer of the SC (sagittal sections), and ipsilateral axons (red) project to a layer (SO) inferior to the contralateral axons. $E$, Summary quantification of the percentage of the SGS layer with ipsilateral projections. In $S A C-\beta 2$-CKOS, more ipsilateral eye axons extended into the SGS layer than in control mice. $\boldsymbol{F}$, Summary quantification of percentage of $S G S$ layer with projections that overlap between the ipsilateral and contralateral eye. In $S A C-\beta 2-C K O$ s, ipsilateral eye axons overlapped to a greater extent with contralateral axons than in control mice, indicating poor eye-specific segregation. R, Rostral; C, caudal; SO, stratum opticum. ${ }^{*} p<0.05$ (ANOVA with Tukey's HSD). Error bars indicate SEM. Scale bars, $500 \mu \mathrm{m}$.

tion at least through the second week after birth in the dLGN. Retinal projections to the SC were also disrupted in DKO mice (Fig. 7 B,E,F; P8 VG1-KO overlap $=3.4 \pm 2.0 \%, n=6$; P8 DKO overlap $=9.0 \pm 8.6 \%, n=9 ; p=0.02$, Student's $t$ test; P15 VG1-WT overlap $=1.1 \pm 0.5 \%, n=8$; P15 DKO overlap $=3.6 \pm 1.9 \%, n=5 ; p=0.03$, Student's $t$ test; P8 VG1-KO $\%$ ipsilateral $=3.4 \pm 2.0, n=10$; 88 DKO \% ipsilateral $=$ $9.0 \pm 8.5, n=6 ; p=0.03$, Student's $t$ test; P15 VG1-WT \% ipsilateral $=1.1 \pm 0.5, n=14 ; \mathrm{P} 15 \mathrm{VG} 1-\mathrm{KO} \%$ ipsilateral $=$ $3.7 \pm 1.9 \%, n=8 ; p=0.02$, Student's $t$ test) at both P8 and $\mathrm{P} 15$. These experiments reveal that persistent Stage II waves, and $\beta 2$-nAChRs in SACs, were sufficient for the normal initi- ation, refinement, and maintenance of eye-specific segregation in the dLGN and SC, but eliminating both Stage II and Stage III waves profoundly disrupts eye segregation.

\section{Discussion}

We sought to test recurrent network models commonly used to describe the propagation and pattern of Stage II cholinergic retinal waves, which are known to drive the refinement of visual circuits in a frequency- and pattern-dependent manner. Cholinergic waves are initiated in SACs (Zhou, 1998; Zhou and Zhao, 2000; Ford and Feller, 2012), the only cholinergic neural type in the retina, and propagate through neurotransmission mediated 


\section{A}
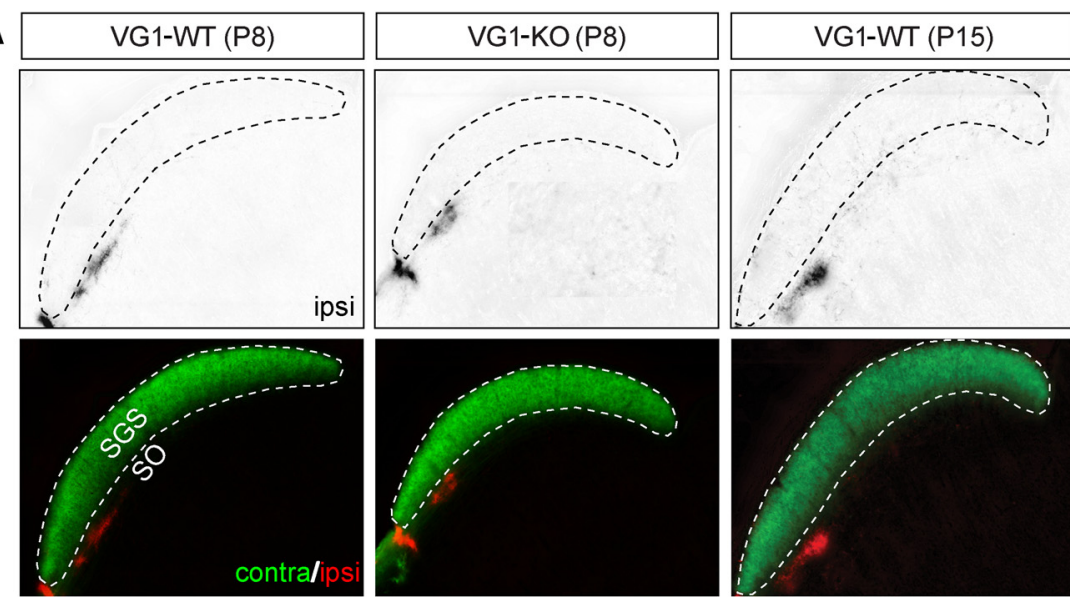

B
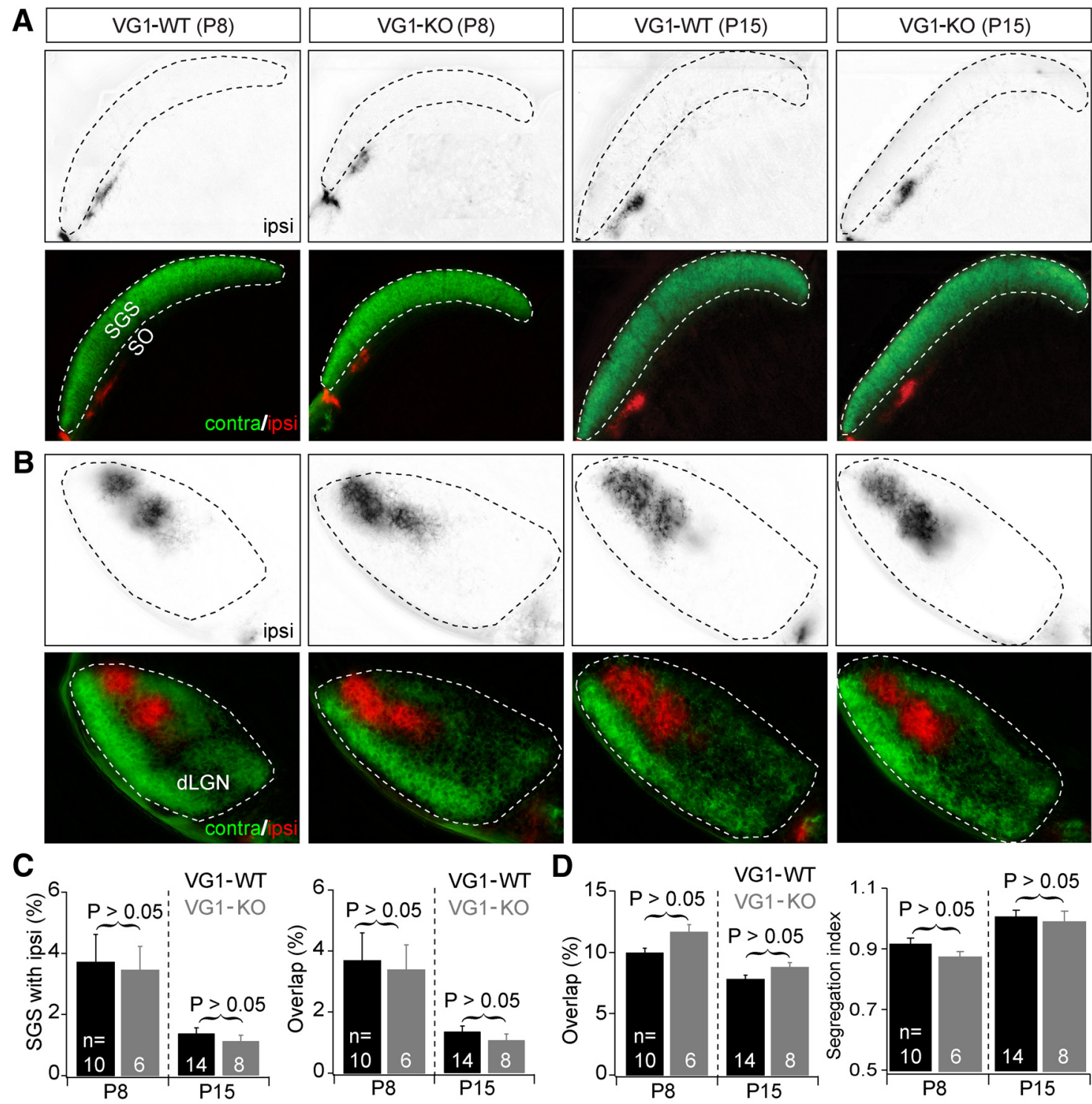

Figure 6. Normal eye-specific projections from retina to SC and dLGN in VG1-KO mice at P8 and P15. $A$, Examples of eye-specific projections from retina to SC in VG1-KO and control (Vglut $1+/+$ : VG1-WT) mice at P8 (left) and P15 (right). Top panels, RGC axon projections from the ipsilateral eye to the SC. Bottom panels, Projections from both eyes to the SC. In all groups, axons from the two eyes were well segregated in the SC. B, Examples of eye-specific projections from retina to dLGN in the same four groups of mice at P8 and P15. Top panels, RGC axon projections from the ipsilateral eye to the dLGN. Bottom panels, Projections from both eyes to the dLGN. In both VG1-KO and wild-type controls, axons from the two eyes were well segregated in the dLGN. $C, \mathbf{D}$, Summary quantification of eye-specific segregation in the SC (C) and dLGN (D) in VG1-KO and control mice at P8 and P15. Eye-specific segregation (\% overlap, Segregation index) was no different in VG1-KO and control mice at both P8 and P15.

by $\beta 2$-containing nAChRs (Feller et al., 1996; Zheng et al., 2006). However, because cholinergic receptors are broadly present at synapses between SACs and many third-order retinal neurons (Wong, 1995; Zheng et al., 2004), including RGCs and other amacrine cells, it has been challenging to directly test how waves propagate in the retina's complex cholinergic network. Here we examined the spatiotemporal properties of cholinergic waves in a mouse model with the specific deletion of $\beta 2$-nAChRs from SACs $(S A C-\beta 2-c K O)$. We observed that retinal waves are truncated in $S A C-\beta 2-c K O$ mice, with wave size inversely proportional to the percentage of SACs lacking $\beta 2$-nAChRs. We also found that RGCs in $S A C-\beta 2-c K O$ mice received input from multiple SACs whose activity was not synchronized, in contrast to RGCs in control mice, the activity of which was highly correlated with neighboring SACs. These results support two-layer wave propagation models in which spontaneous retinal activity first propa- gates within the cholinergic SAC network before being coherently transmitted to RGCs. We also examined the binocular visual map in mice with eliminated or disrupted spontaneous retinal waves in multiple developmental epochs. Genetic deletion of Vglut1 and Stage III retinal waves does not impair eye-specific segregation in either the dLGN or the SC. However, deletion of $\beta 2$ subunits from cholinergic retinal neurons in SAC- $\beta 2-c K O$ mice both alone (P8) and together with deletion of Vglut1 (P15) significantly disrupts eye-specific segregation, demonstrating that glutamatergic wave patterns are not necessary for the refinement and maintenance of eye-specific segregation but that the disruption of persistent Stage II waves in $S A C-\beta 2-c K O s$ without Stage III waves prevents normal visual circuit development.

We specifically deleted $\beta 2$-nAChRs (Chrnb2) from SACs using an age-dependent Cre/loxP system, which gradually increases expression until it reaches $\sim 100 \%$ of SACs at postnatal day 10 . 

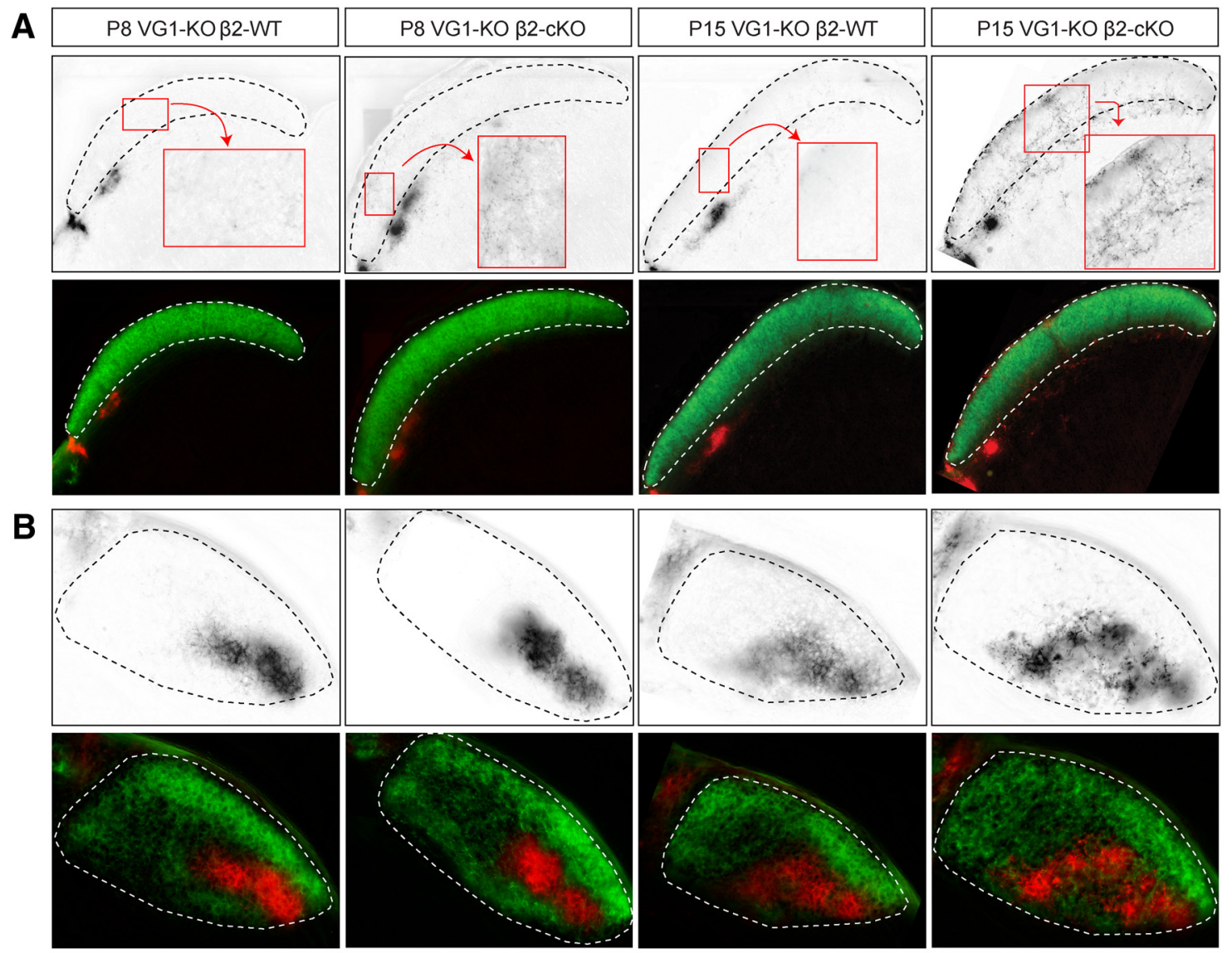

C
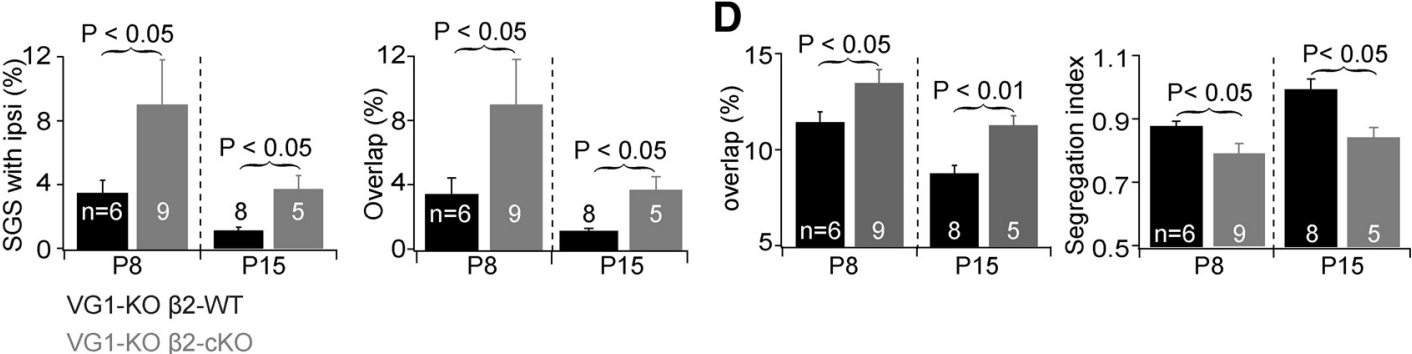

Figure 7. Eye-specific projections from retina to SC were disrupted in VG1-KO/ $\beta 2$-CKOs at P8 and P15. A, Examples of eye-specific projections to the SC in mice with combined manipulations of Vglut1 and $\beta 2$ expression at P8 (left) and P15 (right). Top, RGC axon projections from the ipsilateral eye to the SC. Bottom, RGC projections from both eyes to the SC. In VG1-KO/ $\beta 2$-WT controls $\left(\mathrm{VG} 1^{-1-} / \mathrm{ChAT}-\left(\mathrm{re}^{-} / \beta 2^{\mathrm{fl} /+}\right)\right.$, axons from the contralateral eye projected to the superficial layer (SGS) of the SC and axons from the ipsilateral eye projected to the stratum opticum. Genetic deletion of Vglut 1 alone had no effect on eye-specific projections at P8 (Fig. 6). Additional conditional deletion of $\beta 2$ from SACs disrupted the eye-specific projections at P8 and P15. RGC axon arbors from the ipsilateral eye projected to the SGS layer and overlapped with projections from the contralateral eye in DKO mice. $B$, Examples of eye-specific projections to the dLGN in the same groups of mice at P8 and P15. Top, RGC axon projections from the ipsilateral eye to the dLGN. Bottom, RGC projections from both eyes to the dLGN. Disrupted binocular projections in $S A C-\beta 2-C K 0$ mice at P8 (Fig. 5) were not restored at P15 in mice that also lack VG1 (DKO). C, Summary quantification of eye-specific segregation in the SC. At P8, deletion of VG1 and conditional deletion of $\beta 2$ from SACs significantly increased ipsilateral arbors in the SGS layer. Ipsilateral projections were still disrupted in DKOS at P15 relative to controls. D, Summary quantification of eye-specific segregation in the dLGN. Segregation was worse in mice that lack both VG1 and $\beta 2$ (DKO) in SACs at P8 and P15.

Cre-dependent removal of Chrnb2 did not immediately block cholinergic neurotransmission in SACs, presumably because the mean half-life of mammalian proteins is $46 \mathrm{~h}$ (Schwanhäusser et al., 2011), producing a delay in cholinergic activity disruption. In Cre-expressing SACs, puff application of DMPP, an agonist specific to nicotinic AChRs, elicited excitatory currents that were blocked by $\mathrm{DH} \beta \mathrm{E}$, an $\mathrm{AChR}$-specific antagonist. The remaining currents were likely mediated by residual $\beta 2$-containing AChRs because they were not mediated by either $\beta 4$ - or $\alpha 7$-containing AChRs. This interpretation is supported by the surprising variation DMPP-induced currents displayed at P10, when Cre is expressed in nearly all SACs. SACs expressing Cre late in the first week may retain more $\beta 2$ protein than those expressing Cre soon after birth, suggesting that wide variation in $\beta 2$ protein levels in SACs produces the large variation in nicotinic currents we observed. Our results directly link wave propagation and cholinergic transmission among SACs to provide convincing evidence that mutual cholinergic communication among SACs is responsible for wave initiation and propagation.

The eye-specific segregation phenotype in DKO mice appears to be weaker than in whole-animal $\beta 2-K O$ mice (Xu et al., 2011; Burbridge et al., 2014). This is likely due to the progressive deletion of $\beta 2$-nAChRs from SACs such that retinal waves are normal for much of the first week after birth in DKO mice, but the presence of $\beta 2$ receptors in RGCs in DKO mice might also weaken the eye segregation phenotype. It is notable that eye-specific segrega- 
tion is less disrupted in the dLGN than the SC of DKO mice, but the cause for this difference remains uncertain. One possibility is that segregation in the dLGN is more sensitive to RGC activity levels (and less sensitive to activity patterns), as RGC activity is significantly reduced in $\beta 2-K O$ mice but not very much changed in DKO mice. Another possibility is that the progressive nature of $\beta 2$-nAChR deletion in DKO mice has a stronger effect on the development of RGC arbors in the dLGN than the SC.

\section{Limits of in vivo imaging of RGC activity}

In vivo measurements of retinal activity through imaging of RGC axon arbors in the SC are indirect measures of RGC activity. It is uncertain how much RGC spiking activity is necessary and how many RGCs need to be active to observe their activity through the $\mathrm{Ca}^{2+}$ sensor in RGC axon arbors in the SC. Weak, uncoordinated, and asynchronous activity in isolated RGCs is unlikely to be detected through wide-field $\mathrm{Ca}^{2+}$ imaging in the SC. However, the synchronous coordinated activity typical of retinal waves is readily observable in vivo and displays similar gross features to spiking activity observed in vitro with a multielectrode array. In $S A C-\beta 2-c K O$ mice, domains of synchronous spontaneous retinal activity in vivo appear significantly smaller than retinal waves in wild-type mice, whereas axon arbors are expected, if anything, to be enlarged compared with wild-type mice (Dhande et al., 2011). Moreover, the similar calcium transient amplitudes in the SC of DKO and control mice at both ages was consistent with the comparable firing rates observed in RGCs in vitro. Thus, it is unlikely that the limits of in vivo imaging of RGC activity in the SC substantially contribute to the dramatic differences in observed retinal wave properties between mutant and control mice reported here (Burbridge et al., 2014).

\section{Models of retinal wave initiation and propagation}

One common feature of most retinal wave models is a focus on small average wave size (Godfrey and Swindale, 2007; Hennig et al., 2009; Ford and Feller, 2012), stemming from the typical sizes recorded in vitro $(\sim 1 \%$ of the retinal area). However, results from in vivo experiments show that retinal waves typically traverse a very large $(\sim 30 \%-50 \%)$ region of the retina (Ackman et al., 2012). Given this difference, it is difficult to compare details among models with the present experiments because the models are based on wave properties that are significantly different from the in vivo condition. The Hennig model specifically predicts that decreasing synaptic conductance reduces wave size (Hennig et al., 2009 ), which is what we observe in $S A C-\beta 2-c K O$ mice. In general, the results presented here are consistent with most current models of nicotinic retinal waves that assign responsibility for both wave initiation and propagation to SACs, with RGCs largely "reading out" SAC activity and contributing little to shaping wave properties.

\section{Patterns of retinal waves and visual map development}

RGC axon projections in the brain are initially guided by the graded expression of molecular cues and then refined by patterned neuronal activity before eye opening. Altering the pattern of spontaneous retinal activity disrupts ordered RGC projections, such as the retinotopic map and eye-specific segregation (Zhang et al., 2011; Burbridge et al., 2014; Xu et al., 2015). The immature retina generates three stages of waves distinguished by their pharmacological properties and spatiotemporal patterns, which are thought to be important for stage-dependent developmental functions (Huberman et al., 2008; Burbridge et al., 2014; Xu et al.,
2015). Glutamatergic waves, the last stage of activity that takes place during the week leading up to eye opening, are thought to be critical for both the maintenance and continued refinement of newly formed connections between the eyes and brain (Chapman, 2000; Xu et al., 2010).

Although the unique spatiotemporal patterns of Stage II retinal waves have been well characterized (Stafford et al., 2009; Burbridge et al., 2014), the dynamics of Stage III waves are not as well understood. In vitro calcium imaging and electrophysiological recordings reveal that the spatial coverage and frequency of waves are reduced as they transition from Stage II to Stage III, possibly due to the emergence of GABAergic inhibition, although this difference is far less than the difference between Stage II activity in WT and DKO mice (Syed et al., 2004; Firl et al., 2013; Maccione et al., 2014; Zhou and Xu, 2015). The developmental function of the wave dynamic transition from Stage II to Stage III is not clear. Experiments that disrupted but maintained glutamatergic waves (in contrast to inducing an extended cholinergic wave period) show that continued maintenance and refinement of eye-specific projections depend on normal glutamatergic waves (Xu et al., 2010). Our current results show that blocking the stagedependent change of retinal wave dynamics does not affect eye-specific segregation but that additionally disrupting the extended cholinergic wave activity in VG1-KO mice significantly disrupts segregation. These results suggest that the noticeably distinct spatiotemporal properties of glutamatergic waves (compared with cholinergic waves) are not necessary for the maintenance and/or continued refinement of eye-specific projections, but that some common property of cholinergic and glutamatergic propagating waves is sufficient. The large, slowly propagating cholinergic waves may be well suited for more global competition between ganglion cell projections from the two eyes (Xu et al., 2011, 2015), whereas the smaller and more diversely patterned glutamatergic retinal waves may be optimized for shaping synaptic connections and circuits of different RGCs in a cell typespecific manner or influencing other downstream circuits. Recent studies in mouse retina show that ON and OFF RGCs fire asynchronously during Stage III retinal waves (Kerschensteiner and Wong, 2008; Akrouh and Kerschensteiner, 2013), consistent with a potential role of Stage III waves in the development of ON/OFF circuits in the retina and brain. Future experiments should endeavor to distinguish the contributions of each wave pattern to the diverse retinal and downstream circuits and attempt to clarify the necessity for multiple modes of retinal wave propagation and patterning in the developing visual system.

\section{References}

Ackman JB, Crair MC (2014) Role of emergent neural activity in visual map development. Curr Opin Neurobiol 24:166-175. CrossRef Medline

Ackman JB, Burbridge TJ, Crair MC (2012) Retinal waves coordinate patterned activity throughout the developing visual system. Nature 490: 219-225. CrossRef Medline

Akrouh A, Kerschensteiner D (2013) Intersecting circuits generate precisely patterned retinal waves. Neuron 79:322-334. CrossRef Medline

Bansal A, Singer JH, Hwang BJ, Xu W, Beaudet A, Feller MB (2000) Mice lacking specific nicotinic acetylcholine receptor subunits exhibit dramatically altered spontaneous activity patterns and reveal a limited role for retinal waves in forming $\mathrm{ON}$ and OFF circuits in the inner retina. J Neurosci 20:7672-7681. Medline

Blankenship AG, Feller MB (2010) Mechanisms underlying spontaneous patterned activity in developing neural circuits. Nat Rev Neurosci 11: 18-29. CrossRef Medline

Blankenship AG, Ford KJ, Johnson J, Seal RP, Edwards RH, Copenhagen DR, Feller MB (2009) Synaptic and extrasynaptic factors governing glutamatergic retinal waves. Neuron 62:230-241. CrossRef Medline 
Burbridge TJ, Xu HP, Ackman JB, Ge X, Zhang Y, Ye MJ, Zhou ZJ, Xu J, Contractor A, Crair MC (2014) Visual circuit development requires patterned activity mediated by retinal acetylcholine receptors. Neuron 84:1049-1064. CrossRef Medline

Burgi PY, Grzywacz NM (1994) Model for the pharmacological basis of spontaneous synchronous activity in developing retinas. J Neurosci 14: 7426-7439. Medline

Butts DA, Feller MB, Shatz CJ, Rokhsar DS (1999) Retinal waves are governed by collective network properties. J Neurosci 19:3580-3593. Medline

Chandrasekaran AR, Plas DT, Gonzalez E, Crair MC (2005) Evidence for an instructive role of retinal activity in retinotopic map refinement in the superior colliculus of the mouse. J Neurosci 25:6929-6938. CrossRef Medline

Chapman B (2000) Necessity for afferent activity to maintain eye-specific segregation in ferret lateral geniculate nucleus. Science 287:2479-2482. CrossRef Medline

Cutts CS, Eglen SJ (2014) Detecting pairwise correlations in spike trains: an objective comparison of methods and application to the study of retinal waves. J Neurosci 34:14288-14303. CrossRef Medline

Demas J, Sagdullaev BT, Green E, Jaubert-Miazza L, McCall MA, Gregg RG, Wong RO, Guido W (2006) Failure to maintain eye-specific segregation in nob, a mutant with abnormally patterned retinal activity. Neuron 50: 247-259. CrossRef Medline

Dhande OS, Hua EW, Guh E, Yeh J, Bhatt S, Zhang Y, Ruthazer ES, Feller MB, Crair MC (2011) Development of single retinofugal axon arbors in normal and $\beta 2$ knock-out mice. J Neurosci 31:3384-3399. CrossRef Medline

Feller MB (2002) The role of nAChR-mediated spontaneous retinal activity in visual system development. J Neurobiol 53:556-567. CrossRef Medline

Feller MB (2009) Retinal waves are likely to instruct the formation of eye specific retinogeniculate projections. Neural Dev 4:24. CrossRef Medline

Feller M (2012) Cortical development: the sources of spontaneous patterned activity. Curr Biol 22:R89-R91. CrossRef Medline

Feller MB, Wellis DP, Stellwagen D, Werblin FS, Shatz CJ (1996) Requirement for cholinergic synaptic transmission in the propagation of spontaneous retinal waves. Science 272:1182-1187. CrossRef Medline

Feller MB, Butts DA, Aaron HL, Rokhsar DS, Shatz CJ (1997) Dynamic processes shape spatiotemporal properties of retinal waves. Neuron 19: 293-306. CrossRef Medline

Firl A, Sack GS, Newman ZL, Tani H, Feller MB (2013) Extrasynaptic glutamate and inhibitory neurotransmission modulate ganglion cell participation during glutamatergic retinal waves. J Neurophysiol 109:1969-1978. CrossRef Medline

Ford KJ, Feller MB (2012) Assembly and disassembly of a retinal cholinergic network. Vis Neurosci 29:61-71. CrossRef Medline

Ford KJ, Félix AL, Feller MB (2012) Cellular mechanisms underlying spatiotemporal features of cholinergic retinal waves. J Neurosci 32:850-863. CrossRef Medline

Fremeau RT Jr, Kam K, Qureshi T, Johnson J, Copenhagen DR, StormMathisen J, Chaudhry FA, Nicoll RA, Edwards RH (2004) Vesicular glutamate transporters 1 and 2 target to functionally distinct synaptic release sites. Science 304:1815-1819. CrossRef Medline

Godfrey KB, Eglen SJ (2009) Theoretical models of spontaneous activity generation and propagation in the developing retina. Mol Biosyst 5: 1527-1535. CrossRef Medline

Godfrey KB, Swindale NV (2007) Retinal wave behavior through activitydependent refractory periods. PLoS Comput Biol 3:e245. CrossRef Medline

Goodman CS, Shatz CJ (1993) Developmental mechanisms that generate precise patterns of neuronal connectivity. Cell 72 [Suppl]:77-98.

Grubb MS, Rossi FM, Changeux JP, Thompson ID (2003) Abnormal functional organization in the dorsal lateral geniculate nucleus of mice lacking the beta2 subunit of the nicotinic acetylcholine receptor. Neuron 40: 1161-1172. CrossRef Medline

Hennig MH, Adams C, Willshaw D, Sernagor E (2009) Early-stage waves in the retinal network emerge close to a critical state transition between local and global functional connectivity. J Neurosci 29:1077-1086. CrossRef Medline

Huberman AD, Wang GY, Liets LC, Collins OA, Chapman B, Chalupa LM (2003) Eye-specific retinogeniculate segregation independent of normal neuronal activity. Science 300:994-998. CrossRef Medline

Huberman AD, Feller MB, Chapman B (2008) Mechanisms underlying de- velopment of visual maps and receptive fields. Annu Rev Neurosci 31: 479-509. CrossRef Medline

Kawamoto S, Niwa H, Tashiro F, Sano S, Kondoh G, Takeda J, Tabayashi K, Miyazaki J (2000) A novel reporter mouse strain that expresses enhanced green fluorescent protein upon Cre-mediated recombination. FEBS Lett 470:263-268. CrossRef Medline

Kerschensteiner D, Wong RO (2008) A precisely timed asynchronous pattern of ON and OFF retinal ganglion cell activity during propagation of retinal waves. Neuron 58:851-858. CrossRef Medline

Kirkby LA, Sack GS, Firl A, Feller MB (2013) A role for correlated spontaneous activity in the assembly of neural circuits. Neuron 80:1129-1144. CrossRef Medline

Li H, Fertuzinhos S, Mohns E, Hnasko TS, Verhage M, Edwards R, Sestan N, Crair MC (2013) Laminar and columnar development of barrel cortex relies on thalamocortical neurotransmission. Neuron 79:970-986. CrossRef Medline

Maccione A, Hennig MH, Gandolfo M, Muthmann O, van Coppenhagen J, Eglen SJ, Berdondini L, Sernagor E (2014) Following the ontogeny of retinal waves: pan-retinal recordings of population dynamics in the neonatal mouse. J Physiol 592:1545-1563. CrossRef Medline

McLaughlin T, Torborg CL, Feller MB, O’Leary DD (2003) Retinotopic map refinement requires spontaneous retinal waves during a brief critical period of development. Neuron 40:1147-1160. CrossRef Medline

Moser N, Mechawar N, Jones I, Gochberg-Sarver A, Orr-Urtreger A, Plomann M, Salas R, Molles B, Marubio L, Roth U, Maskos U, Winzer-Serhan U, Bourgeois JP, LeSourd AM, De Biasi M, Schröder H, Lindstrom J, Maelicke A, Changeux JP, Wevers A (2007) Evaluating the suitability of nicotinic acetylcholine receptor antibodies for standard immunodetection procedures. J Neurochem 102: 479-492. CrossRef Medline

Mrsic-Flogel TD, Hofer SB, Creutzfeldt C, Cloz̧-Tayarani I, Changeux JP, Bonhoeffer T, Hübener M (2005) Altered map of visual space in the superior colliculus of mice lacking early retinal waves. J Neurosci 25 : 6921-6928. CrossRef Medline

Penn AA, Riquelme PA, Feller MB, Shatz CJ (1998) Competition in retinogeniculate patterning driven by spontaneous activity. Science 279: 2108-2112. CrossRef Medline

Rossi FM, Pizzorusso T, Porciatti V, Marubio LM, Maffei L, Changeux JP (2001) Requirement of the nicotinic acetylcholine receptor beta 2 subunit for the anatomical and functional development of the visual system. Proc Natl Acad Sci U S A 98:6453-6458. CrossRef Medline

Rossi J, Balthasar N, Olson D, Scott M, Berglund E, Lee CE, Choi MJ, Lauzon D, Lowell BB, Elmquist JK (2011) Melanocortin-4 receptors expressed by cholinergic neurons regulate energy balance and glucose homeostasis. Cell Metab 13:195-204. CrossRef Medline

Schwanhäusser B, Busse D, Li N, Dittmar G, Schuchhardt J, Wolf J, Chen W, Selbach M (2011) Global quantification of mammalian gene expression control. Nature 473:337-342. CrossRef Medline

Siegel F, Heimel JA, Peters J, Lohmann C (2012) Peripheral and central inputs shape network dynamics in the developing visual cortex in vivo. Curr Biol 22:253-258. CrossRef Medline

Stafford BK, Sher A, Litke AM, Feldheim DA (2009) Spatial-temporal patterns of retinal waves underlying activity-dependent refinement of retinofugal projections. Neuron 64:200-212. CrossRef Medline

Stellwagen D, Shatz CJ (2002) An instructive role for retinal waves in the development of retinogeniculate connectivity. Neuron 33:357-367. CrossRef Medline

Sun C, Warland DK, Ballesteros JM, van der List D, Chalupa LM (2008) Retinal waves in mice lacking the $\beta 2$ subunit of the nicotinic acetylcholine receptor. Proc Natl Acad Sci U S A 105:13638-13643. CrossRef Medline

Syed MM, Lee S, Zheng J, Zhou ZJ (2004) Stage-dependent dynamics and modulation of spontaneous waves in the developing rabbit retina. J Physiol 560:533-549. CrossRef Medline

Torborg CL, Hansen KA, Feller MB (2005) High frequency, synchronized bursting drives eye-specific segregation of retinogeniculate projections. Nat Neurosci 8:72-78. CrossRef Medline

Weliky M, Katz LC (1999) Correlational structure of spontaneous neuronal activity in the developing lateral geniculate nucleus in vivo. Science 285 : 599-604. CrossRef

Wong RO (1995) Cholinergic regulation of $\left[\mathrm{Ca}^{2+}\right]_{\mathrm{i}}$ during cell division and differentiation in the mammalian retina. J Neurosci 15:2696-2706. Medline 
Wong RO (1999) Retinal waves and visual system development. Annu Rev Neurosci 22:29-47. CrossRef Medline

Wong WT, Myhr KL, Miller ED, Wong RO (2000) Developmental changes in the neurotransmitter regulation of correlated spontaneous retinal activity. J Neurosci 20:351-360. Medline

Xu HP, Chen H, Ding Q, Xie ZH, Chen L, Diao L, Wang P, Gan L, Crair MC, Tian N (2010) The immune protein CD3zeta is required for normal development of neural circuits in the retina. Neuron 65:503515. CrossRef Medline

Xu HP, Furman M, Mineur YS, Chen H, King SL, Zenisek D, Zhou ZJ, Butts DA, Tian N, Picciotto MR, Crair MC (2011) An instructive role for patterned spontaneous retinal activity in mouse visual map development. Neuron 70:1115-1127. CrossRef Medline

Xu HP, Burbridge TJ, Chen MG, Ge X, Zhang Y, Zhou ZJ, Crair MC (2015) Spatial pattern of spontaneous retinal waves instructs retinotopic map refinement more than activity frequency. Dev Neurobiol 75:621-640. CrossRef Medline

Zhang J, Ackman JB, Xu HP, Crair MC (2011) Visual map development depends on the temporal pattern of binocular activity in mice. Nat Neurosci 15:298-307. CrossRef Medline

Zheng JJ, Lee S, Zhou ZJ (2004) A developmental switch in the excitability and function of the starburst network in the mammalian retina. Neuron 44:851-864. CrossRef Medline

Zheng J, Lee S, Zhou ZJ (2006) A transient network of intrinsically bursting starburst cells underlies the generation of retinal waves. Nat Neurosci 9:363-371. CrossRef Medline

Zhou EK, Xu HP (2015) GABAergic regulation of spontaneous spike patterns in the developing rabbit retina. Neurosci Lett 600:137-142. CrossRef Medline

Zhou ZJ (1998) Direct participation of starburst amacrine cells in spontaneous rhythmic activities in the developing mammalian retina. J Neurosci 18:4155-4165. Medline

Zhou ZJ, Zhao D (2000) Coordinated transitions in neurotransmitter systems for the initiation and propagation of spontaneous retinal waves. J Neurosci 20:6570-6577. Medline 